\title{
Spawning origins of pelagic juvenile cod Gadus morhua inferred from spatially explicit age distributions: potential influences on year-class strength and recruitment
}

\author{
Gavin A. Begg*, Gudrun Marteinsdottir \\ Marine Research Institute, Skulagata 4, PO Box 1390, 121 Reykjavik, Iceland
}

\begin{abstract}
Incongruity between the reconstructed spawning period of pelagic juvenile (0-group) cod Gadus morhua and the observed spawning period for adult cod on the main spawning grounds south of Iceland have indicated that large numbers of the surviving juvenile population may, in some years, originate from other smaller inshore spawning grounds located within fjords of the west, north and east coasts. We examine this hypothesis by using age/length and temperature/growth relationships, based on aging of 0-group cod from 1995 and 1997, to analyze historical demographic data from 0-group fish surveys (1970 to 1998) and determine the spawning distribution and origin of pelagic juvenile cod. Data on early life-history characteristics in conjunction with temporal and spatial distribution of pelagic juvenile cod are used to create new abundance indices representing the inshore and offshore juvenile cod-population components. Partitioning of the historical 0-group index into these population components at a finer geographic scale than has been used previously provides new information for estimating the relative contribution of the main spawning component versus the smaller in-fjord spawning components towards variable recruitment levels in the Icelandic cod stock. Spawning diversity, or multiple spawning components, are important for recruitment success as they disperse the mortality risk of the early life-history stages, which are thought to be the principal determinants of year-class strength.
\end{abstract}

KEY WORDS: Stock $\cdot$ Recruitment $\cdot 0$-group $\cdot$ Cod $\cdot$ Gadus morhua $\cdot$ Population dynamics

\section{INTRODUCTION}

Fundamental to understanding the population dynamics, and subsequent assessment and management, of exploited marine fish stocks is the relationship between spawning stock biomass and recruitment. Although, spawning stock biomass and recruitment are functionally related (Ricker 1954, Beverton \& Holt 1957, Cushing 1971, Fogarty 1993, Myers et al. 1995, Myers \& Barrowman 1996), this relationship is often poorly defined; most likely due in part to the inherent variability associated with ecological and/or environmental factors (Jakobsen 1996, Sparholt 1996). Recently, this has resulted in alternate, potentially more

\footnotetext{
*E-mail: gavin@hafro.is
}

informative, measures of recruitment being sought, such as egg production indices (Marshall et al. 1998), and the need to disentangle individual factors that may be contributing to the inherent variability of year-class strength and stock-recruitment relationships, such as age and size diversity of spawning fish (Marteinsdottir \& Thorarinsson 1998). Similarly, the diversity of spawning components and subsequent origins of progeny derived from these components contribute further to the inherent variability within stock-recruitment relationships, particularly as these relationships are based on a single-unit stock assumption (Begg et al. 1999, Stephenson 1999). However, often this assumption is violated by greater spawning diversity (i.e. multiple spawning components) than that which typically has been assessed in historically established management 
units. In this study, we examine this assumption by investigating the origin of pelagic juvenile (0-group) cod (Gadus morhua) in Icelandic waters with an aim to determining the relative contribution of individual spawning components to the overall recruitment of the stock.

In recent years, the Icelandic cod stock has been severely depleted, with recruitment levels low since the mid-1980s (Schopka 1994, Baldursson et al. 1996). Historically, the main spawning grounds of cod in Iceland have been located along the south coast (Sæmundsson 1924, Jónsson 1982), although smaller inshore and in-fjord spawning grounds in other locations around the country also appear to contribute to the overall recruitment of the stock (Marteinsdottir et al. in press b). However, the relative contribution of these smaller spawning components to the main spawning component is not known. Pelagic eggs and larvae derived from the main spawning component off the south coast, during April and May, drift clockwise around the country with the westward flowing coastal currents and the northward flowing Irminger Current (Fridgeirsson 1984, Astthorsson et al. 1994) (see Fig. 1). Generally, the majority of pelagic juveniles are found in the Arcto-boreal waters off the northwest, north, and northeast coasts of Iceland, although in some years large concentrations are also found near Greenland where the Irminger Current flows westward (Vilhjalmsson \& Fridgeirsson 1976, Vilhjalmsson \& Magnusson 1984, 1985, Astthorsson et al. 1994). In contrast to this expected dispersal pattern, a declining size gradient is typically found for pelagic juvenile cod from the west to the east coasts that has been suggested to derive from temperature-induced growth differences (Astthorsson et al. 1994). However, a recent study by Marteinsdottir et al. (in press b), based on the 1995 to 1997 0-group fish surveys, found a corresponding declining age gradient for pelagic juvenile cod from the west to the east coasts, indicative of differential spawning components. Consequently, the 0-group fish surveys provide an important source of information by which to examine the life history, origin, and stock complexity of pelagic juvenile cod that may explain some of the variability in year-class strength and subsequent recruitment to the stock.

Pelagic juvenile (0-group) fish surveys have been conducted in the northeast Atlantic since 1965 to provide annual estimates of year-class strength and recruitment (Helgason \& Sveinbjörnsson 1987, Sundby et al. 1989, Jakupsstovu \& Reinert 1994). These estimates predict recruitment at older ages, but do not correlate well in some years (Campana et al. 1989, Sundby et al. 1989, Astthorsson et al. 1994, Anderson \& Dalley 1997). Some of this variation may be due to density-dependent predation after settlement (Bogstad et al. 1994), while further variation may be due to the coarse geographic scale at which the 0-group abundance indices are calculated and the need within these calculations to account for multiple spawning components. In Iceland, the 0-group abundance indices are presently calculated for 5 large geographic regions that incorporate both inshore and offshore waters (Vilhjalmsson \& Fridgeirsson 1976, Sveinbjörnsson \& Jónsson 1998). However, numerous studies have shown that cod typically have separate inshore and offshore spawning components that may be reproductively isolated from one another (Hurley \& Campana 1989, Hutchings et al. 1993, Anderson et al. 1995, Marteinsdottir \& Petursdottir 1995, Ruzzante et al. 1996, Anderson \& Dalley 1997, Dalley \& Anderson 1997). Similarily, in waters north of Iceland, an offshore component may represent juvenile cod that drifted into the northern waters from the main spawning grounds in the south, while an inshore component may to a greater extent include juveniles that originated from local spawning within fjords. Hence, there exists a need to re-examine the historical 0-group abundance indices for Icelandic cod at a finer geographic scale than has previously been examined, separating inshore and offshore components, in order to explain variable recruitment levels in the stock-particularly in view of the more recent study of Marteinsdottir et al. (in press b) that suggests the existence of multiple spawning components.

In this study, we examine the historical 0-group survey data to determine the origin of pelagic juvenile cod in Icelandic waters. The traditional paradigm of cod stockstructure was tested to determine whether pelagic juvenile cod originate from spawning grounds other than those of the main spawning grounds off the south coast. The findings of Marteinsdottir et al. (in press b) were extended by using length/age and temperature/growth relationships based on their aging of 0-group cod to provide information on historically reconstructed spawning times and locations. The statistical reconstruction of inter-annual variation in spatial distribution, abundance, length, and age composition of pelagic juvenile cod, modeled with environmental conditions were used to infer final locations of progeny surviving to the pelagic juvenile stage. Furthermore, this enabled predictions about the dispersal of early life-history stages and relationships between their spatial distribution and abundance to be evaluated as a function of stock and environmental conditions, while evaluating the significance of spawning diversity or multiple spawning components to year-class strength and recruitment.

\section{MATERIAL AND METHODS}

Historical distribution, abundance, and length composition data for pelagic juvenile cod Gadus morhua 
collected from the 0-group fish surveys between July and September 1970 to 1998 were analyzed to determine spawning origins of cod in Icelandic waters. Sampling was conducted using a Harstad pelagic trawl $(18 \times 18 \mathrm{~m}$ opening; $0.5 \times 0.5 \mathrm{~cm}$ cod-end mesh $)$ at $<90$ stations between 1970 and 1972, and >150 stations since 1973. Since 1980, a fixed survey route has been used, although the extent of the survey into the Irminger Sea has fluctuated. Standardised survey methods were used throughout the survey period, with trawls generally made at depths of 20 to $50 \mathrm{~m}$. Acoustic records were used to monitor changes in fish distribution and abundance and to determine sampling frequency. A sample was taken whenever acoustic records changed or approximately every 20 nautical miles. Abundance measures recorded at each station were the number of cod captured per nautical mile towed. Total lengths (TL) were adjusted (based on a measured growth rate of $0.65 \mathrm{~mm} \mathrm{~d}^{-1}$; Marteinsdottir et al. in press b) to the mean cruise date of the surveys (20 August) estimated for the entire time series, enabling a direct comparison of historical data between years. The 0-group data were separated into inshore (1a to $7 a$ ) and offshore (1b to $7 b, 8)$ statistical regions on the basis of known spawning locations and dispersal patterns of eggs and larvae (Marteinsdottir et al. in press a) and the $100 \mathrm{~m}$ depth contour, enabling a more accurate representation of spawning and spatial stock structure than previously achieved for the Icelandic cod stock (Table 1, Fig. 1).

Temperature data were obtained from fixed survey stations located along standardized transects used in annual hydrographic research cruises to characterize ambient environmental conditions experienced by surviving pelagic juvenile cod (Fig. 1). Water temperatures in the upper $100 \mathrm{~m}$ of the water column were averaged for each day (in each year) that data were recorded to represent annual daily temperature cycles. Annual daily temperature cycles were derived for waters north (combined Statistical Regions 2 to 6) and south (combined Statistical Regions 1 and 7) of Iceland, respectively, on the basis of known oceanographic conditions (Malmberg et al. 1996, Anonymous 1999), and concerns associated with low sample sizes in some years for any given statistical region (Fig. 1). Although, it was desirable to estimate daily temperature cycles

Table 1. Annual number (n) of 0-group cod Gadus morhua measured in each region (1a to 8), 1970 to 1998. na = no data available

\begin{tabular}{|c|c|c|c|c|c|c|c|c|c|c|c|c|c|c|c|c|}
\hline \multirow{2}{*}{ Year } & & & & & & & & \multirow{2}{*}{$\begin{array}{c}\mathrm{n} \text { (region) } \\
4 \mathrm{~b}\end{array}$} & \multirow[b]{2}{*}{$5 a$} & \multirow[b]{2}{*}{$5 b$} & \multirow[b]{2}{*}{$6 a$} & \multirow[b]{2}{*}{$6 b$} & \multirow[b]{2}{*}{$7 a$} & \multirow[b]{2}{*}{$7 b$} & \multirow[b]{2}{*}{8} & \multirow{2}{*}{ Total } \\
\hline & $1 \mathrm{a}$ & $1 b$ & $2 \mathrm{a}$ & $2 \mathrm{~b}$ & $3 a$ & $3 b$ & $4 \mathrm{a}$ & & & & & & & & & \\
\hline 1970 & 8 & na & 830 & 101 & 536 & 123 & 998 & 394 & 189 & 16 & na & na & na & na & na & 3195 \\
\hline 1971 & 102 & 170 & 407 & 17 & 134 & 131 & 428 & 87 & na & na & na & na & 1 & na & 1 & 1478 \\
\hline 1972 & 179 & 126 & 47 & 2 & 63 & 23 & 248 & 129 & na & 100 & na & na & na & na & na & 917 \\
\hline 1973 & 113 & 140 & 685 & 89 & 508 & 130 & 556 & 267 & 422 & 167 & 271 & 305 & 295 & 194 & 278 & 4420 \\
\hline 1974 & 39 & na & 54 & 100 & 19 & 390 & 412 & 157 & 8 & 12 & na & 4 & na & na & 8 & 1203 \\
\hline 1975 & 38 & 25 & 85 & 344 & 324 & 185 & 861 & 85 & 280 & 171 & 39 & 13 & na & na & 63 & 2513 \\
\hline 1976 & 233 & 199 & 846 & 259 & 998 & 581 & 1060 & 868 & 400 & 659 & 112 & 231 & 58 & 54 & 149 & 6707 \\
\hline 1977 & 1 & na & 173 & 175 & 475 & 92 & 664 & 152 & 199 & 137 & 55 & 56 & 27 & na & 15 & 2221 \\
\hline 1978 & 3 & 2 & 760 & 263 & 466 & 118 & 686 & 219 & 285 & 174 & 30 & 94 & na & na & 46 & 3146 \\
\hline 1979 & 39 & 9 & 69 & 151 & 382 & 151 & 418 & 404 & 25 & 28 & na & 1 & 1 & na & 42 & 1720 \\
\hline 1980 & 20 & 26 & 352 & 76 & 188 & 16 & 347 & 270 & 210 & 147 & 43 & 11 & na & 17 & 18 & 1741 \\
\hline 1981 & 44 & 80 & 235 & 16 & 122 & 5 & 215 & 14 & 46 & na & na & na & na & na & 153 & 930 \\
\hline 1982 & 2 & 2 & 68 & na & 23 & 1 & 28 & 19 & 15 & 1 & na & na & na & na & 1 & 160 \\
\hline 1983 & 60 & 8 & 133 & 5 & 327 & 14 & 512 & 75 & 97 & 148 & na & 4 & na & na & 5 & 1388 \\
\hline 1984 & 109 & 4 & 4 & 257 & 686 & 18 & 902 & 328 & 490 & 433 & 351 & 360 & 13 & 30 & 734 & 4719 \\
\hline 1985 & 40 & 15 & 363 & 725 & 326 & 196 & 375 & 582 & 64 & 259 & na & na & na & 2 & 375 & 3322 \\
\hline 1986 & 86 & 15 & 43 & 95 & 349 & 16 & 237 & 173 & 6 & 16 & na & 117 & 2 & 34 & 61 & 1250 \\
\hline 1987 & na & 23 & 6 & 28 & 179 & 48 & 204 & 237 & 78 & 77 & 15 & 4 & na & na & 138 & 1037 \\
\hline 1988 & 29 & 74 & 39 & 6 & 61 & 4 & 229 & 11 & 15 & 31 & na & na & na & na & 1 & 500 \\
\hline 1989 & 52 & 22 & 163 & 36 & 446 & 10 & 209 & 25 & 101 & 23 & 6 & 1 & na & na & 20 & 1114 \\
\hline 1990 & 7 & 8 & 49 & 26 & 215 & 23 & 145 & 122 & 19 & 45 & 105 & 2 & na & na & 37 & 803 \\
\hline 1991 & 3 & na & 3 & 3 & 38 & 10 & 52 & 23 & na & na & 1 & 2 & na & na & 2 & 137 \\
\hline 1992 & 2 & 4 & 234 & 47 & 240 & 39 & 143 & 42 & na & 49 & 158 & 3 & na & na & 1 & 962 \\
\hline 1993 & 29 & 26 & 505 & 379 & 68 & 42 & 670 & 291 & 86 & 25 & 29 & 5 & na & na & 27 & 2182 \\
\hline 1994 & na & na & 46 & 1 & 421 & 5 & 433 & 26 & 12 & 16 & 4 & 2 & na & 3 & 1 & 970 \\
\hline 1995 & 68 & 16 & 182 & 1 & 232 & 13 & 1038 & 286 & 385 & 140 & 190 & 9 & 21 & 1 & na & 2582 \\
\hline 1996 & 5 & 1 & 34 & 3 & 103 & 1 & 269 & 9 & 53 & 3 & na & na & 4 & 5 & na & 490 \\
\hline 1997 & 150 & 10 & 617 & 593 & 887 & 466 & 1749 & 949 & 855 & 383 & 459 & 22 & 2 & na & 108 & 7250 \\
\hline 1998 & 248 & 56 & 1375 & 963 & 1219 & 598 & 1700 & 1433 & 849 & 877 & 281 & 39 & na & na & 6 & 9644 \\
\hline Total & 1709 & 1061 & 8407 & 4761 & 10035 & 3449 & 15788 & 37677 & 5189 & 4137 & 2149 & 1285 & 424 & 340 & 2290 & \\
\hline
\end{tabular}



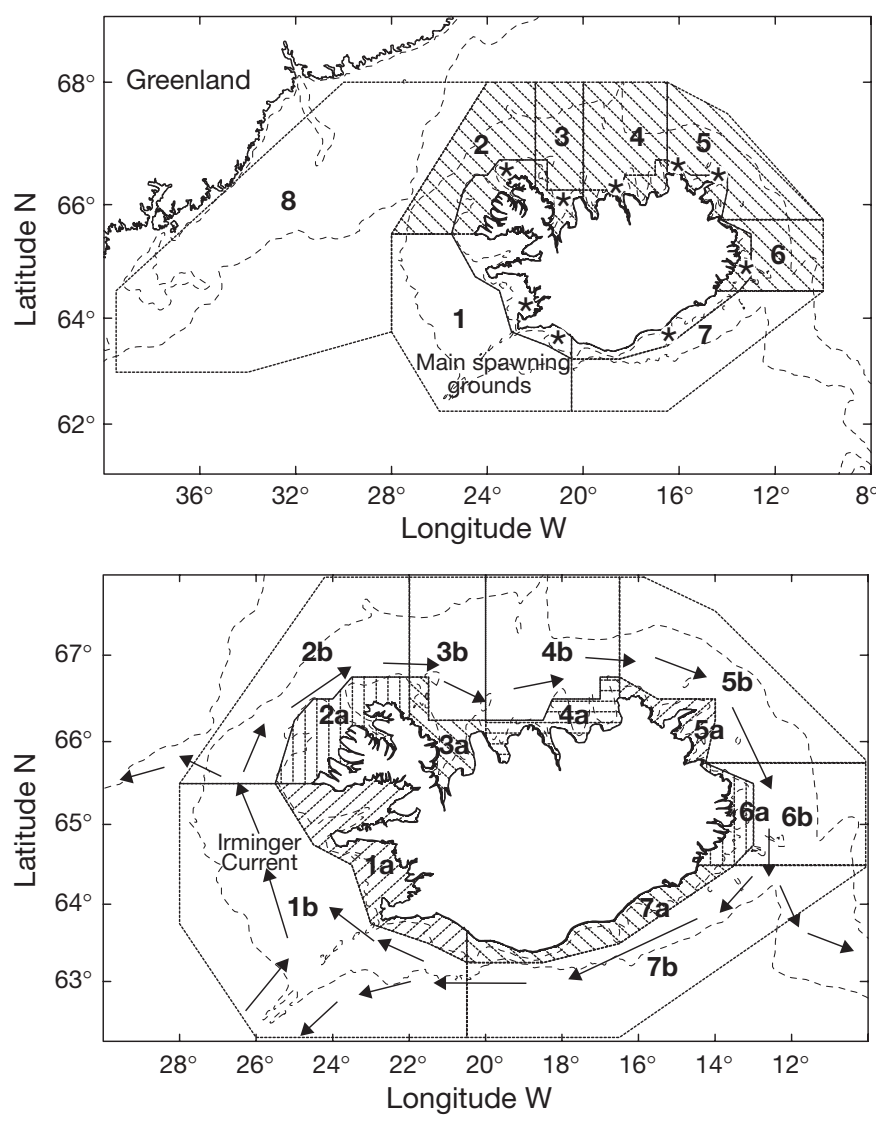

Fig. 1. General ocean circulation patterns (Malmberg et al. 1996), and inshore (1a to $7 \mathrm{a}$ ) and offshore (1b to $7 \mathrm{~b}, 8$ ) statistical regions of 0-group cod Gadus morhua sampled in Icelandic waters. *: Locations of hydrographic stations used to characterize yearly temperature data for northern (hatched Regions 2 to 6) and southern (Regions 1 and 7) areas. Main spawning grounds located in Region 1

for each statistical region separately, it was not possible because of sample limitations. However, previous studies have shown that there are relatively well defined horizontal gradients between waters north and south of Iceland (corresponding to the above combined regions), whereby the northern waters are colder and more variable in any given year than the southern waters (Malmberg \& Kristmannsson 1992, Kristmannsson 1998). Consequently, to reconstruct historical daily temperature cycles and estimate temperature at capture, hatching and spawning of pelagic juvenile cod, fourth order polynomial regressions were fitted to the daily temperature data for each year and area (i.e. north or south). For those cod found in Region 8, the daily temperature cycles for the southern area were used, as the conditions there were assumed to be most similar because of known ocean circulation patterns (Malmberg et al. 1996). Also, for some years (northern area: 1970, 1971, 1973; southern area: 1970), daily tem- perature cycles could not be estimated directly because of limited data; hence, temperature cycles for other years approximating similar environmental conditions were used instead (based on Astthorsson et al. 1994, Anonymous 1999). Furthermore, for some years (northern area: 1998; southern area: 1979, 1982, 1983), daily temperature cycles were based on the mean monthly data for the mean day of sampling for each month rather than the raw daily temperature data, because of an improved fit of each regression. For similar reasons, the daily temperature cycle for 1972 (northern area) was based on data also collected from adjacent offshore stations.

Spatial distribution and relative abundance (number per nautical mile) of pelagic juvenile cod were initially compared on an annual basis, irrespective of region, to determine the general strength and direction of progeny dispersal following spawning. Annual abundance indices of pelagic juvenile cod were then calculated for each statistical region (1a to 8) following the methods of Astthorsson et al. (1994). Prior to these calculations the abundance data were first log-transformed to normalize the distributions and reduce the effects of the relatively few large catches. An abundance index $\left(A_{\mathrm{r}}\right)$ of pelagic juvenile cod in each region was then calculated for each year according to the following equations:

$$
\begin{aligned}
X_{\mathrm{r}} & =1 / N_{\mathrm{r}} \sum \ln \left(X_{i}\right) \\
P_{\mathrm{r}} & =N_{\mathrm{r}} / N_{\mathrm{t}} \\
A_{\mathrm{r}} & =X_{\mathrm{r}} P_{\mathrm{r}}\left(G_{\mathrm{r}} / G_{\mathrm{t}}\right)
\end{aligned}
$$

where, in each region (1a to 8), $X_{\mathrm{r}}=$ logarithmic mean abundance of pelagic juvenile $\operatorname{cod}_{i} N_{\mathrm{r}}=$ number of stations where catch was $>0 ; X_{i}=$ number of cod captured per nautical mile towed at Stn $i$ where catch also was $>0 ; P_{\mathrm{r}}=$ proportion of non-zero tows; $N_{\mathrm{t}}=$ total number of stations; $G_{\mathrm{r}}=$ geographic area $\left(\mathrm{km}^{2}\right)$ of the region; and $G_{\mathrm{t}}=$ total geographic area of all the regions.

Adjusted (20 August) total length distributions of pelagic juvenile cod were determined for fish in each year and region (1a to 8) to assess differences in demographic characteristics indicative of differential spawning times and locations. Likewise, a growth model was derived for pelagic juvenile cod based on 1995 and 1997 aging data from Marteinsdottir et al. (in press b), and applied across years and regions (1a to 8) to provide historical age distributions of pelagic juvenile cod. Analysis of covariance (ANCOVA) was initially used to examine differences in growth rates of cod from the different regions. Multiple regression was then used to examine the effect of temperature at capture because of the known influence temperature has on growth (Campana \& Hurley 1989) and the widely differing temperatures between waters north and south of Iceland (Anonymous 1999). 
Hatch and spawning (day-of-the-year, DOY) distributions of pelagic juvenile cod were then examined to determine spatial origins of cod in Icelandic waters. Hatch distributions of pelagic juvenile cod in each region (1a to 8 ) were determined directly by subtracting the age of each fish from the day at capture, and were not corrected for mortality effects because all samples were collected in the low-mortality juvenile stage (Campana \& Jones 1992, Campana 1996). In contrast, spawning distributions were determined by subtracting an incubation period $\left(T_{\text {hatch }}\right)$ from the estimated hatch day of each fish. Consequently, we estimated the potential distribution of pelagic juvenile cod that may have originated from the main spawning grounds in the south (Region 1) by using incubation periods and reconstuctured spawning distributions based only on the southern area (i.e. null hypothesis, $H_{0}$ : all pelagic juvenile cod originate from the main spawning grounds in the south). The incubation periods, based on the estimated daily temperature cycles for the southern area in each year, were estimated for the mean mid-incubation day-the mid-day between the estimated annual mean hatch day (this study) and the presumed mean spawning day (Jónsson 1982, Marteinsdottir et al. in press b). Accordingly, the incubation period was related to the ambient water temperature following Pepin et al. (1997):

$$
T_{\text {hatch }}=46.1 \mathrm{e}^{-0.17 \text { temperature }}
$$

where 'temperature' was that estimated from the daily temperature cycles for the southern area in each year for the estimated annual mean mid-incubation day. The proportion of pelagic juvenile cod estimated to originate from spawning later than the 99 and $95 \%$ spawning distribution percentiles for those cod from the main spawning grounds (Region 1) were then assumed to originate from spawning grounds other than the main spawning grounds.

\section{RESULTS}

\section{Daily temperature cycles}

Historically, lower daily temperatures were consistently experienced by those pelagic juvenile cod, Gadus morhua, inhabiting waters off the northwest, north, and northeast coasts (Regions 2 to 6) than those off the southwest, south, and southeast coasts (Regions 1 and 7: Table 2, Fig. 2). In each area, water temperatures steadily increased from April to June (presumptive spawning period), showing a consistent seasonal heating cycle across all years. Throughout this period, water temperatures ranged from -1.65 to $5.60^{\circ} \mathrm{C}$ in the northern area, and from 4.07 to $8.44^{\circ} \mathrm{C}$ in the southern area. Generally, water temperatures varied by $4^{\circ} \mathrm{C}$ between the 2 areas on any given day during the presumptive spawning and hatching periods, with mean temperatures across years in the northern area approximating $1.70^{\circ} \mathrm{C}(1 \mathrm{April}), 2.47^{\circ} \mathrm{C}(10 \mathrm{May})$, and $3.28^{\circ} \mathrm{C}$ (1 June), and in the southern area 5.42, 6.51, and 7.28 ${ }^{\circ} \mathrm{C}$, respectively (Fig. 2 ).

\section{Distribution and abundance}

In August/September, pelagic juvenile cod were distributed around the west, north, and east coasts of Iceland (Fig. 3). In most years, large aggregations of pelagic juvenile cod were typically found off the northern coast of Iceland (Regions 2 to 5), although in some years large aggregations were also found near Greenland (Region 8), where they had probably drifted from the main spawning grounds in the south (Region 1) with the northern and western branch of the Irminger Current. Few pelagic juvenile cod were found in waters off the southeast coast (Region 7), indicating that eggs and larvae are not retained in this region during the summer months following hatching. Likewise, few pelagic juvenile cod were typically found on the main spawning grounds as no doubt prior to sampling they had already drifted north with the coastal and Irminger currents following spawning (Fig. 3).

Generally, there has been a progressive decline in relative abundance of pelagic juvenile cod throughout the years $(F=5.26, \mathrm{df}=1,27, \mathrm{p}<0.0298)$, although there have been intermittent increases, particularly in more recent years (Fig. 4). Abundance indices tended to be greater for regions in the north than for those in the south, with high abundance indices estimated near Greenland (Region 8) in some years. Similarly, abundance indices tended to be greater in the offshore regions $(1 \mathrm{~b}$ to $7 \mathrm{~b})$ than in their corresponding inshore regions (1a to 7a) (Fig. 4). Notably, in those years where abundance indices were greatest (i.e. 1973, 1976, 1984, 1985, 1997, 1998) large aggregations of pelagic juvenile cod appeared to be more evenly distributed along the entire northern coast (Regions 2 to 6) (Fig. 3).

\section{Length composition}

Pelagic juvenile cod tended to decrease in length from the west to the east coasts (Regions 1 to 7) (Fig. 5). This decreasing, clockwise, length gradient of pelagic juvenile cod around the country was evident for all years combined, and for nearly all individual years (except 1976) throughout the survey period, indicative of progeny originating from differential spawning or hatching times and locations and/or the result of spa- 
Table 2. Annual temperature relationships represented by fourth order polynomial regressions used to reconstruct historical day-of-the-year (DOY) temperatures at capture, hatching, and spawning for 0-group cod Gadus morhua in northern (Regions 2 to 6) and southern (Regions 1 and 7) areas, 1970 to 1998

\begin{tabular}{|c|c|c|c|c|c|c|c|}
\hline \multirow[t]{2}{*}{ Year } & \multirow[t]{2}{*}{$\mathrm{n}$} & \multirow[t]{2}{*}{$r^{2}$} & \multirow[b]{2}{*}{ Intercept } & \multirow[b]{2}{*}{ DOY } & \multicolumn{2}{|c|}{ Parameter estimate } & \multirow[b]{2}{*}{$\mathrm{DOY}^{4}$} \\
\hline & & & & & $\mathrm{DOY}^{2}$ & $\mathrm{DOY}^{3}$ & \\
\hline \multicolumn{8}{|c|}{ Northern } \\
\hline $1970^{\mathrm{a}}$ & 20 & 0.67 & 0.050 & 0.058 & -0.0008 & 0.000005 & -0.0000000088 \\
\hline $1971^{\mathrm{a}}$ & 20 & 0.67 & 0.050 & 0.058 & -0.0008 & 0.000005 & -0.0000000088 \\
\hline $1972^{b}$ & 8 & 0.95 & 0.339 & 0.163 & -0.0028 & 0.000018 & -0.0000000376 \\
\hline $1973^{c}$ & 14 & 0.77 & -17.880 & 0.674 & -0.0071 & 0.000031 & -0.0000000468 \\
\hline 1974 & 14 & 0.77 & -17.880 & 0.674 & -0.0071 & 0.000031 & -0.0000000468 \\
\hline 1975 & 20 & 0.67 & 0.050 & 0.058 & -0.0008 & 0.000005 & -0.0000000088 \\
\hline 1976 & 22 & 0.80 & 20.642 & -0.582 & 0.0052 & -0.000017 & 0.0000000185 \\
\hline 1977 & 26 & 0.76 & 4.424 & -0.117 & 0.0012 & -0.000003 & 0.0000000022 \\
\hline 1978 & 21 & 0.76 & 2.858 & -0.042 & 0.0003 & 0.000001 & -0.0000000031 \\
\hline 1979 & 25 & 0.64 & 1.683 & 0.042 & -0.0010 & 0.000007 & -0.0000000122 \\
\hline 1980 & 22 & 0.91 & 6.074 & -0.175 & 0.0019 & -0.000006 & 0.0000000055 \\
\hline 1981 & 21 & 0.81 & 10.960 & -0.386 & 0.0037 & -0.000012 & 0.0000000128 \\
\hline 1982 & 24 & 0.92 & -0.311 & 0.068 & -0.0011 & 0.000007 & -0.0000000124 \\
\hline 1983 & 16 & 0.74 & 2.290 & -0.011 & -0.0004 & 0.000005 & -0.0000000098 \\
\hline 1984 & 12 & 0.85 & -24.051 & 0.892 & -0.0093 & 0.000039 & -0.0000000545 \\
\hline 1985 & 15 & 0.85 & -2.843 & 0.178 & -0.0019 & 0.000009 & -0.0000000139 \\
\hline 1986 & 17 & 0.68 & 7.504 & -0.188 & 0.0017 & -0.000005 & 0.0000000045 \\
\hline 1987 & 17 & 0.84 & 25.127 & -0.780 & 0.0076 & -0.000027 & 0.0000000325 \\
\hline 1988 & 16 & 0.89 & -3.577 & 0.173 & -0.0021 & 0.000011 & -0.0000000182 \\
\hline 1989 & 13 & 0.97 & 0.793 & 0.028 & -0.0006 & 00005 & -0.0000000088 \\
\hline 1990 & 14 & 0.85 & 9.592 & -0.225 & 0.0017 & -0.000003 & 0.0000000002 \\
\hline 1991 & 15 & 0.70 & -10.594 & 0.430 & -0.0046 & 0.000020 & -0.0000000294 \\
\hline $19 s$ & 16 & 0.86 & 10.592 & -0.260 & & -0.0 & \\
\hline 1993 & 18 & 0.74 & -10.127 & 0.413 & -0.0046 & 0.000021 & $-0.000000031 \mathrm{~s}$ \\
\hline 1994 & 11 & 0.72 & -1.489 & 0.113 & -0.0011 & 0.000005 & -0.0000000074 \\
\hline 1995 & 28 & 0.83 & 8.448 & -0.187 & 0.0012 & -0.000001 & -0.0000000035 \\
\hline 1996 & 12 & 0.78 & -11.248 & 0.538 & -0.0061 & 0.000027 & -0.0000000403 \\
\hline 1997 & 12 & 0.81 & 13.054 & -0.408 & 0.0039 & -0.000013 & 0.0000000139 \\
\hline $1998^{d}$ & 7 & 0.74 & 19.095 & -0.550 & 0.0056 & -0.000022 & 0.0000000286 \\
\hline \multicolumn{8}{|c|}{ Southern } \\
\hline $1970^{\mathrm{e}}$ & 9 & 0.87 & 10.878 & -0.171 & 0.0018 & -0.000006 & 0.0000000068 \\
\hline 1971 & 9 & 0.8 & & -0.1 & & -0 & 068 \\
\hline 1972 & 6 & 0.99 & 7.072 & -0.034 & 0.0003 & 0.000001 & -0.0000000042 \\
\hline & 7 & & & 0.143 & -0.00 & & -0.0000000435 \\
\hline 1974 & 10 & 0.80 & -1.791 & 0.239 & -0.0026 & 0.000014 & -0.0000000248 \\
\hline 1975 & 12 & 0.73 & 1.044 & 0.070 & -0.0003 & 0.000001 & -0.0000000011 \\
\hline & 15 & 0.6 & & -0.254 & 0.0029 & -0.0 & 0.0000000151 \\
\hline 1977 & 18 & 0.69 & 13.172 & -0.306 & 0.0034 & -0.000013 & 0.0000000157 \\
\hline & 20 & 0.7 & & -0.0 & 0.00 & -0.000001 & -0.0000000006 \\
\hline $1979^{d}$ & 7 & $0 . c$ & & -0.036 & -0.0001 & 0.000003 & -0.000000005 \\
\hline 1980 & 15 & 0.95 & 4.202 & 0.006 & 0.0000 & 0.000001 & -0.0000000029 \\
\hline & 22 & 0.7 & & -0.006 & & -0.000001 & 0.0000000002 \\
\hline $1982^{\mathrm{d}}$ & 6 & 0.99 & 7.033 & -0.108 & 0.0016 & -0.000007 & 0.0000000113 \\
\hline $1983^{d}$ & 7 & 0.78 & 6.195 & -0.073 & 0.0009 & -0.000003 & 0.0000000037 \\
\hline & 11 & & & -0.078 & & & \\
\hline 1985 & 17 & 0.82 & 6.220 & -0.046 & 0.0005 & -0.000001 & 0.0000000001 \\
\hline & 14 & 0.87 & & 0.101 & -0.0012 & 0.000007 & -0.0000000118 \\
\hline & 13 & & 4.661 & 0.028 & -0.0004 & 0.000003 & -0.0000000068 \\
\hline 1988 & 13 & 0.70 & -3.473 & 0.272 & -0.0027 & 0.000012 & -0.0000000185 \\
\hline & 10 & 0.6 & & -0.246 & & -0.000010 & \\
\hline & 20 & 0.8 & 1.049 & -0.491 & 0.0047 & -0.000017 & 0.0000000200 \\
\hline 1991 & 18 & 0.73 & 6.793 & -0.360 & 0.0035 & -0.000012 & $0.000000013 \mathrm{~s}$ \\
\hline 1992 & 23 & 0.71 & & -0.231 & 0.0022 & -0.000007 & 0.0000000074 \\
\hline 1993 & 17 & 0.68 & 9.841 & -0.154 & 0.0014 & -0.000004 & 0.0000000033 \\
\hline 1994 & 14 & 0.77 & 7.217 & -0.106 & 0.0013 & -0.000005 & 0.0000000058 \\
\hline & 14 & & & & 0.0012 & -0.000004 & 0.0000000036 \\
\hline 1996 & 19 & 0.69 & -1.974 & 0.264 & -0.0026 & 0.000011 & -0.0000000157 \\
\hline 1997 & 12 & 0.76 & 4.701 & -0.063 & 0.0008 & -0.000003 & 0.0000000020 \\
\hline 1998 & 12 & 0.64 & 8.521 & -0.144 & 0.0016 & -0.000006 & 0.0000000065 \\
\hline
\end{tabular}

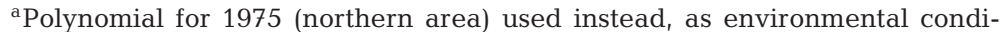
tions were most similar

${ }^{b}$ Polynomial for 1972 (northern area), also based on data from offshore stations 'Polynomial for 1974 (northern area) used instead, as environmental conditions were most similar

${ }^{\mathrm{d}}$ Polynomial based on mean monthly data for mean day of sampling for each month

ePolynomial for 1971 (southern area) used instead, as environmental conditions were most similar tially differential growth rates. Furthermore, when the mean lengths of pelagic juvenile cod were estimated for individual survey stations in each year this length gradient was even more pronounced (Fig. 6). Interestingly, the length composition of pelagic juvenile cod comprising the Greenland component (Region 8, mean $[ \pm \mathrm{SD}$ ] all years combined $=59 \pm 10 \mathrm{~mm}$ ) was very similar to that of those cod originating from the main spawning component (Region 1, $59 \pm 11 \mathrm{~mm}$ ), providing further support for pelagic juvenile cod from these 2 regions having similar spawning origins.

\section{Growth and age composition}

Growth rates did not appear to differ between pelagic juvenile cod from the northern (Regions 2 to 6) and southern (Region 1) areas (1995 and 1997 data combined: ANCOVA, $F=2.91$, df $=1$, $528, \mathrm{p}>0.0884$ ); thereby justifying the assimilation of these data for statistical purposes (Fig. 7). Consequently, we decided to combine all the data into a single growth model for purposes of consistency and because of sample limitations, to be used across all the years for historical reconstruction of age at capture, hatching, and spawning of pelagic juvenile cod. In addition, temperature at capture was found to have a significant effect on growth, and so was also incorporated into the final growth model (Table 3).

Pelagic juvenile cod tended to decrease in age from the west to the east coasts (Regions 1 to 7: Table 4, Fig. 8). Similar to length, this decreasing, clockwise, age gradient of pelagic juvenile cod around the country was evident for all years combined and for nearly all of the individual years throughout the survey. Once again, the age composition of pelagic juvenile cod comprising the Greenland component (Region 8 , mean $[ \pm \mathrm{SD}]$ all years combined $=93 \pm 14 \mathrm{~d}$ ) was very similar to that of cod originating from the main spawning component (Region 1, $94 \pm$ 16 d) (Table 4). 

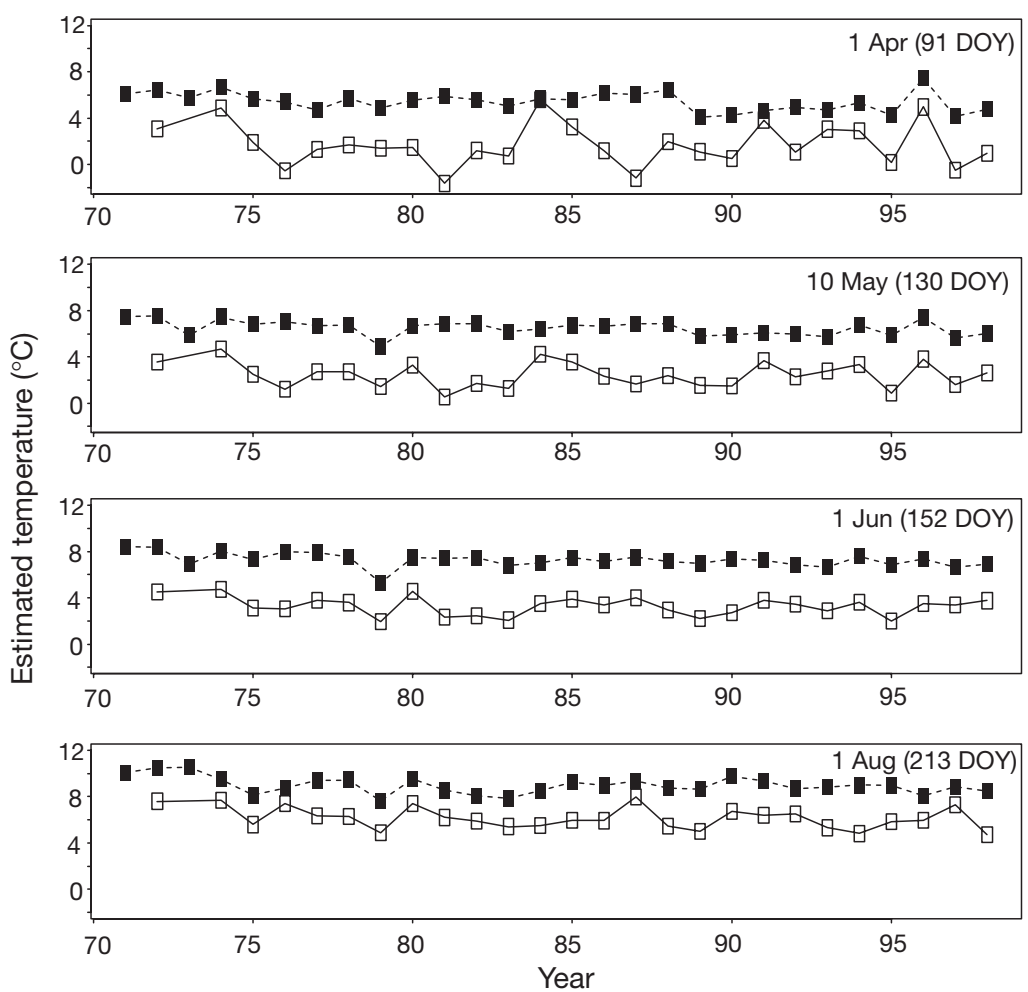

Fig. 2. Annual estimated temperatures derived from temporal and spatial specific fourth order polynomial regressions for specific days-of-the-year (DOY)

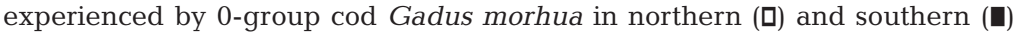
areas, 1970 to 1998

\section{Hatch distribution}

Pelagic juvenile cod tended to hatch progressively later from the west to the east coasts for all years combined and for most of the individual years (Regions 1

Table 3. Growth relationship (total length/age) of 0-group cod Gadus morhua used to reconstruct historical age at capture for determination of hatching and spawning distributions. Relationship based on 1995 and 1997 ageing data from Marteinsdottir et al. (in press b) for Regions 1 to 6. [TL = $15.8723+0.4256$ (age) -2.5401 (temperature) +0.0307 (age $\times$ temperature) $\left.\left(r^{2}=0.83\right)\right]$

\begin{tabular}{|lcrrcc|}
\hline Source & df & \multicolumn{1}{c}{ MS } & $F$ & $\mathrm{p}$ \\
\hline Model & 3 & 18872.92 & 836.49 & 0.0001 \\
Error & 528 & 22.56 & & \\
Age & 1 & 349.06 & 15.47 & 0.0001 \\
Temperature & 1 & 100.06 & 4.43 & 0.0357 \\
Age $\times$ Temperature & 1 & 98.49 & 4.37 & 0.0372 \\
& & & & \\
Parameter & Estimate & $\mathrm{SE}$ & $\mathrm{p}$ \\
\hline Intercept & 15.8723 & 8.5965 & 0.0654 \\
Age & 0.4256 & 0.1082 & 0.0001 \\
Temperature & -2.5401 & 1.2062 & 0.0357 \\
Age $\times$ Temperature & 0.0307 & 0.0147 & 0.0372 \\
\hline
\end{tabular}

to 7: Table 5, Fig. 9). Those cod found off the southwest coast, near the main spawning grounds, tended to hatch around 18 May (Region 1, mean [SD] all years combined $=138 \pm 16$ DOY), while those further north and east hatched progressively later throughout May, June and early July (Region 2, $144 \pm 17$; Region 3, $155 \pm 17$; Region 4, $160 \pm 17$; Region 5, $161 \pm$ 18; Region 6, $163 \pm$ 18; Region 7, $162 \pm 26$ DOY). Hatch distributions of pelagic juvenile cod found near Greenland (Region 8, $139 \pm$ $14 \mathrm{DOY})$ tended to closely reflect the hatch distributions of those cod found near the main spawning grounds in the south (Region 1: Fig. 9).

\section{Spawning distribution}

Pelagic juvenile cod assumed to originate from the main spawning grounds in the south (Region 1) were estimated to incubate prior to hatching for approximately $15 \pm 2 \mathrm{~d}$ (all years combined). This incubation period was based on the estimated annual daily temperature cycles for the southern area for the mean mid-incubation day (range 124 to $141 \mathrm{DOY}$ ) in each year, which was the mid-day between the annual mean hatch day (143 to $167 \mathrm{DOY}$ ) and the presumed mean spawning day (105 DOY). Based on these assumptions, pelagic juvenile cod were estimated to spawn progressively later from the west to the east coasts for all years combined, and for most of the individual years (Regions 1 to 7 : Table 5, Fig. 10). Those cod found off the southwest coast, near the main spawning grounds, were estimated to originate from spawning periods around 3 May (Region 1, mean [SD] all years combined $=123 \pm$ 16 DOY), while those further north and east spawned progressively later throughout May (Region 2, $129 \pm$ 17; Region 3, $140 \pm 17$; Region 4, $144 \pm 17$; Region 5, $146 \pm 18$; Region 6, $147 \pm 18$; Region 7, $146 \pm 25$ DOY) Estimated spawning distributions of pelagic juvenile cod found near Greenland (Region 8, $123 \pm 14$ DOY) closely reflected the spawning distributions of those cod found near the main spawning grounds in the south (Region 1); indicative of similar spawning origins (Fig. 10).

Hence, the overall estimated spawning distribution of pelagic juvenile cod from the main spawning grounds in the south (Region 1), across all years, ranged from 22 March to 8 June (99\% percentiles: Fig. 10). Assum- 

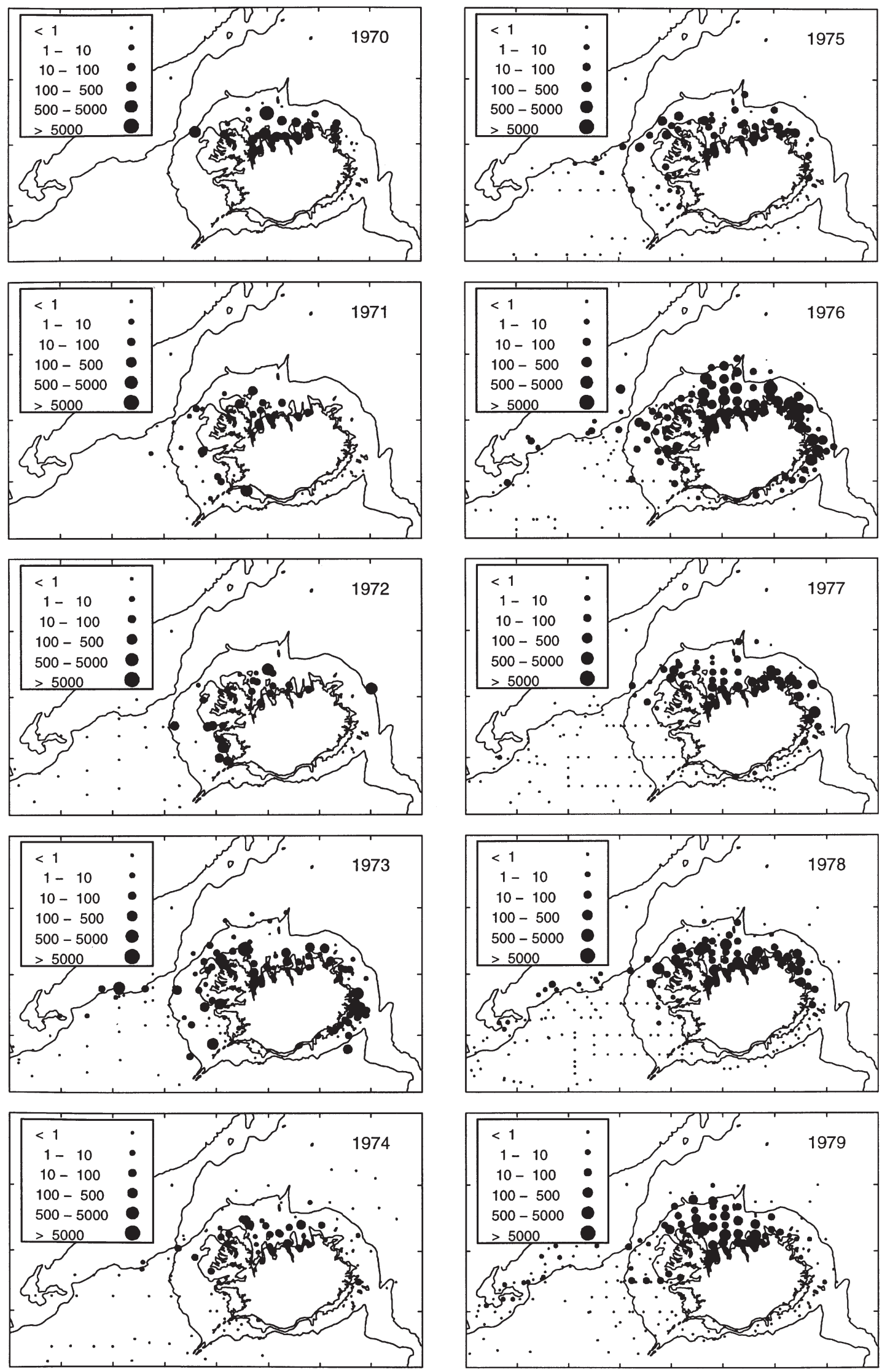

Fig. 3. (Above and 2 following pages). Annual relative distribution and abundance (numbers nautical mile ${ }^{-1}$ ) of 0 -group cod Gadus morhua, 1970 to 1998 

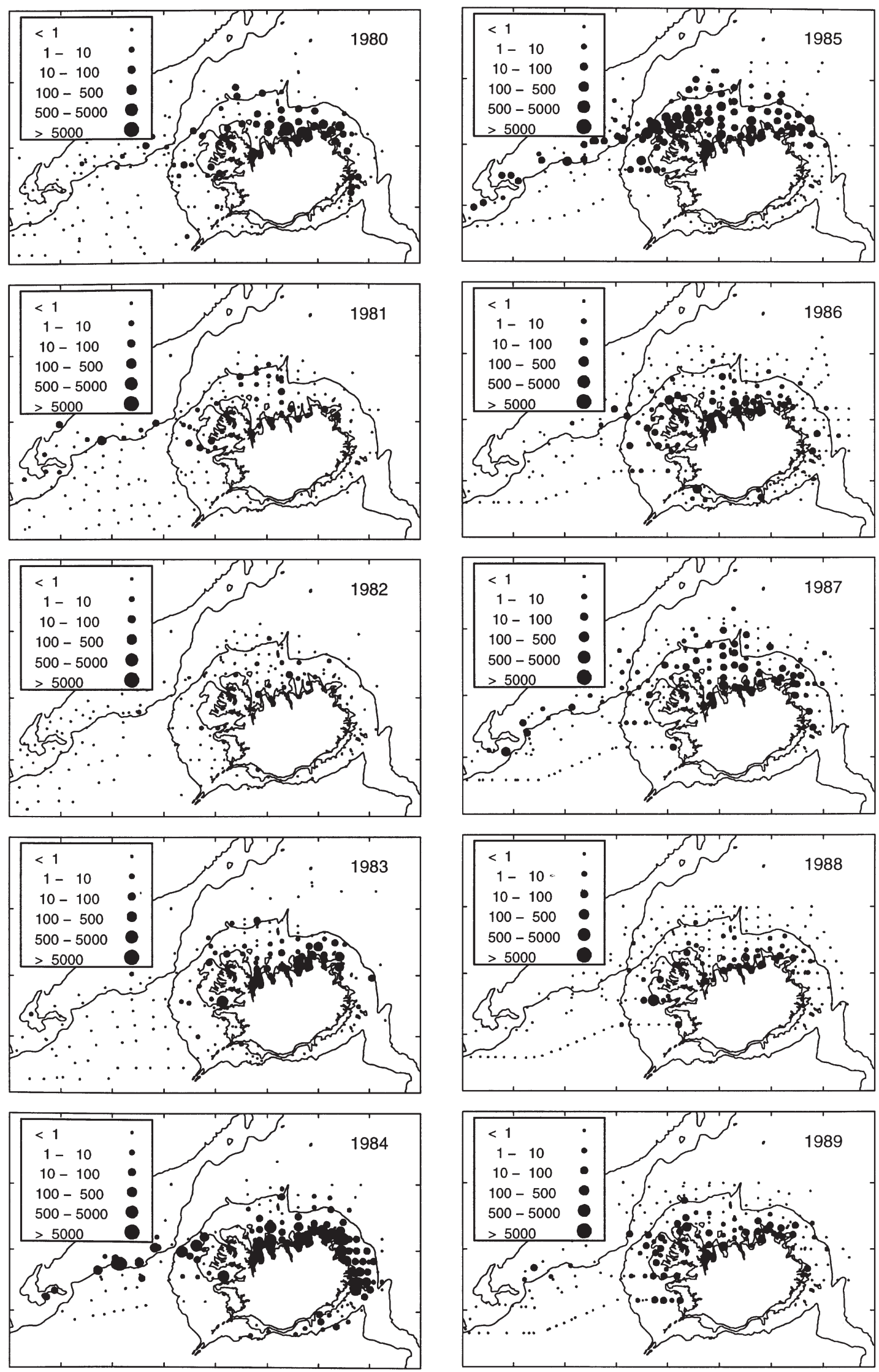

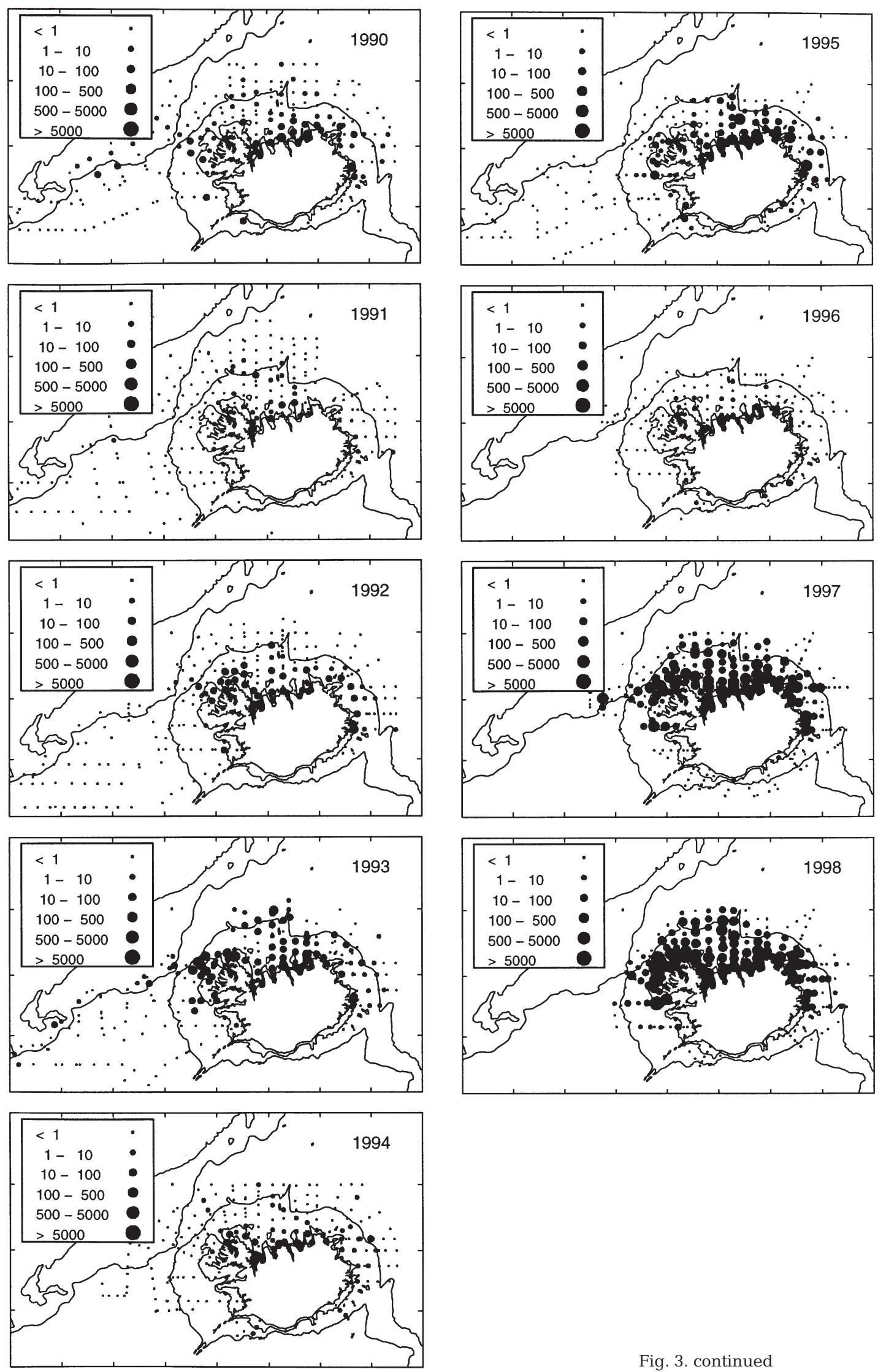

Fig. 3. continued 

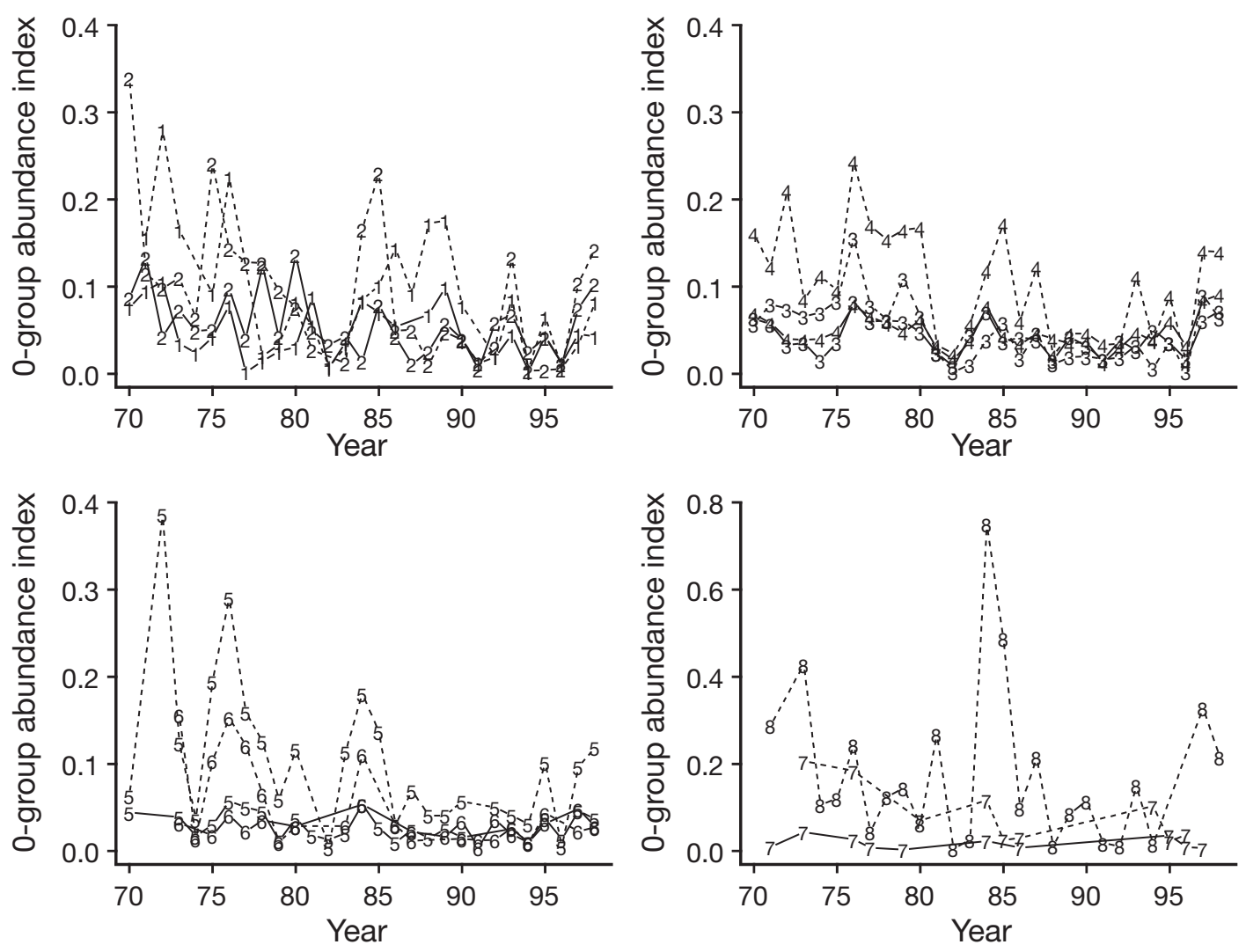

Fig. 4. Annual abundance indices estimated for 0-group cod Gadus morhua in inshore (continuous lines) and offshore (dashed lines) regions, and all regions combined (o), 1970 to 1998. Numbers on individual lines $=$ indices for each region (1 to 8). Statistics describe relationship between abundance index and year

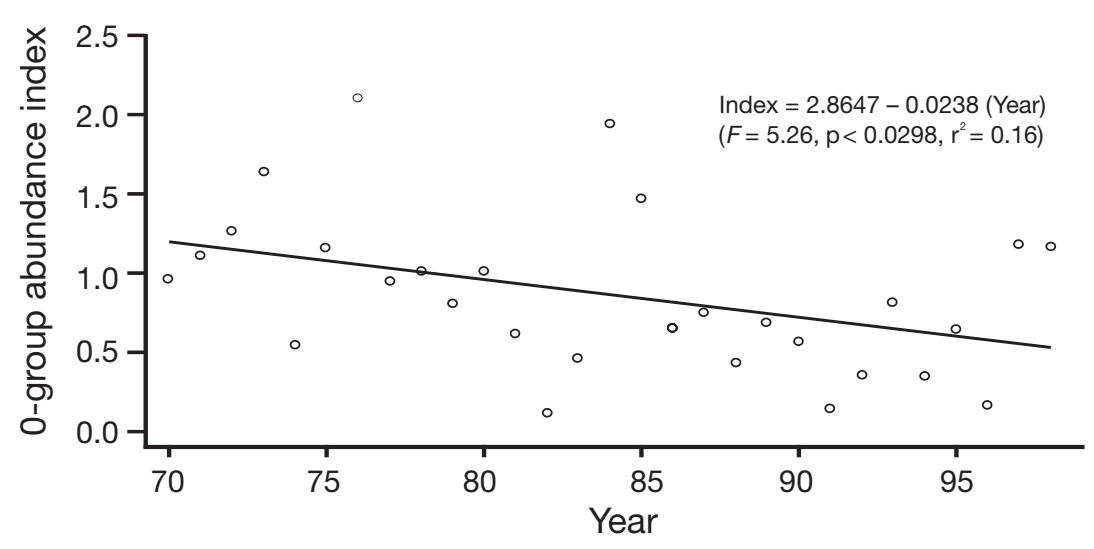

ing this period to be indicative of cod originating from the main spawning grounds (Region 1), considerable proportions of pelagic juvenile cod from the other regions (2 to 7 ) were spawned outside this period, both overall and for most of the individual years, indicating that they most likely originated from other spawning grounds around the country (Table 6). The relative proportion of pelagic juvenile cod estimated to originate from spawning grounds other than the main spawning grounds in the south progressively increased from the west to the east coasts (all years combined: Region 2, 3\%; Region 7, 37\%). However, based on a less conservative, although probably more realistic estimate $(95 \%$ estimated spawning distribution percentiles), the proportion of cod estimated to originate from spawning grounds other than the main spawning grounds in the south was even greater (Region 2, $11 \%$; Region 7, 52\%: Fig. 11).

\section{DISCUSSION}

Historically, variable but in some years relatively large proportions of pelagic juvenile Gadus morhua in Icelandic waters originate from spawning grounds other than those of the main spawning grounds off the 
Table 4. Annual mean adjusted (20 August) age (d) of 0-group cod Gadus morhua for each region (1a to 8), 1970 to 1998. na $=$ no data available

\begin{tabular}{|c|c|c|c|c|c|c|c|c|c|c|c|c|c|c|c|c|}
\hline \multirow{2}{*}{ Year } & & & & & & & \multirow{2}{*}{\multicolumn{2}{|c|}{$\begin{array}{c}\text { Region } \\
4 \mathrm{a} \quad 4 \mathrm{~b}\end{array}$}} & \multirow[b]{2}{*}{$5 a$} & \multirow[b]{2}{*}{$5 b$} & \multirow[b]{2}{*}{$6 a$} & \multirow[b]{2}{*}{$6 \mathrm{~b}$} & \multirow[b]{2}{*}{$7 a$} & \multirow[b]{2}{*}{$7 b$} & \multirow[b]{2}{*}{8} & \multirow{2}{*}{ Total } \\
\hline & $1 \mathrm{a}$ & $1 \mathrm{~b}$ & $2 \mathrm{a}$ & $2 b$ & $3 a$ & $3 b$ & & & & & & & & & & \\
\hline 1970 & 55 & na & 85 & 72 & 68 & 74 & 73 & 74 & 64 & 67 & na & na & na & na & na & 75 \\
\hline 1971 & 69 & 84 & 69 & 94 & 71 & 71 & 72 & 69 & na & na & na & na & 122 & na & 89 & 73 \\
\hline 1972 & 103 & 101 & 75 & 96 & 74 & 68 & 73 & 66 & na & 68 & na & na & na & na & na & 81 \\
\hline 1973 & 97 & 93 & 92 & 94 & 67 & 98 & 53 & 69 & 49 & 51 & 58 & 54 & 58 & 52 & 100 & 69 \\
\hline 1974 & 114 & na & 88 & 94 & 76 & 84 & 79 & 69 & 77 & 62 & na & 57 & na & na & 87 & 82 \\
\hline 1975 & 97 & 88 & 87 & 94 & 68 & 84 & 56 & 59 & 60 & 64 & 67 & 60 & na & na & 91 & 69 \\
\hline 1976 & 96 & 89 & 87 & 86 & 91 & 83 & 90 & 85 & 88 & 89 & 90 & 78 & 111 & 83 & 77 & 88 \\
\hline 1977 & 81 & na & 106 & 98 & 75 & 72 & 69 & 67 & 64 & 59 & 63 & 58 & 104 & na & 77 & 75 \\
\hline 1978 & 107 & 80 & 94 & 91 & 78 & 93 & 78 & 76 & 75 & 73 & 69 & 71 & na & na & 86 & 83 \\
\hline 1979 & 87 & 82 & 62 & 63 & 54 & 52 & 50 & 54 & 45 & 41 & na & 50 & 81 & na & 71 & 55 \\
\hline 1980 & 84 & 88 & 73 & 77 & 68 & 64 & 73 & 72 & 85 & 81 & 83 & 76 & na & 76 & 87 & 75 \\
\hline 1981 & 93 & 96 & 102 & 77 & 81 & 82 & 82 & 74 & 74 & na & na & na & na & na & 89 & 89 \\
\hline 1982 & 91 & 98 & 70 & na & 78 & 81 & 79 & 76 & 67 & 46 & na & na & na & na & 72 & 74 \\
\hline 1983 & 95 & 89 & 86 & 75 & 83 & 86 & 80 & 74 & 76 & 71 & na & 51 & na & na & 82 & 80 \\
\hline 1984 & 95 & 75 & 100 & 96 & 91 & 75 & 86 & 87 & 85 & 88 & 83 & 86 & 67 & 91 & 98 & 89 \\
\hline 1985 & 114 & 95 & 94 & 106 & 84 & 86 & 70 & 76 & 69 & 73 & na & na & na & 77 & 95 & 88 \\
\hline 1986 & 106 & 95 & 90 & 86 & 84 & 63 & 81 & 79 & 79 & 82 & na & 72 & 94 & 100 & 82 & 84 \\
\hline 1987 & na & 114 & 104 & 82 & 77 & 68 & 66 & 67 & 65 & 61 & 67 & 61 & na & na & 94 & 73 \\
\hline 1988 & 81 & 93 & 101 & 86 & 70 & 86 & 72 & 84 & 65 & 72 & na & na & na & na & 79 & 78 \\
\hline 1989 & 84 & 86 & 85 & 82 & 75 & 87 & 72 & 70 & 66 & 69 & 71 & 68 & na & na & 85 & 76 \\
\hline 1990 & 79 & 93 & 91 & 84 & 81 & 80 & 72 & 73 & 66 & 67 & 61 & 64 & na & na & 86 & 75 \\
\hline 1991 & 85 & na & 73 & 75 & 65 & 68 & 63 & 69 & na & na & 110 & 98 & na & na & 96 & 67 \\
\hline 1992 & 73 & 56 & 71 & 77 & 69 & 69 & 71 & 60 & na & 59 & 61 & 81 & na & na & 61 & 68 \\
\hline 1993 & 90 & 100 & 73 & 87 & 66 & 61 & 73 & 69 & 68 & 59 & 64 & 68 & na & na & 75 & 75 \\
\hline 1994 & na & na & 67 & 50 & 52 & 52 & 56 & 44 & 63 & 66 & 77 & 74 & na & 97 & 102 & 55 \\
\hline 1995 & 78 & 104 & 70 & 51 & 62 & 61 & 66 & 66 & 64 & 58 & 52 & 82 & 106 & 86 & na & 65 \\
\hline 1996 & 124 & 74 & 81 & 63 & 73 & 64 & 74 & 62 & 58 & 54 & na & na & 115 & 135 & na & 74 \\
\hline 1997 & 102 & 91 & 92 & 86 & 79 & 83 & 75 & 79 & 73 & 70 & 73 & 66 & 45 & na & 96 & 79 \\
\hline 1998 & 99 & 100 & 88 & 89 & 71 & 81 & 69 & 72 & 62 & 64 & 56 & 57 & na & na & 104 & 75 \\
\hline Total & 95 & 92 & 86 & 91 & 75 & 80 & 72 & 73 & 69 & 72 & 68 & 71 & 71 & 68 & 93 & \\
\hline
\end{tabular}

south coast. Our results contrast with traditional paradigms of cod stock structure and spawning diversity (i.e. Jónsson 1982), while advancing the findings of Marteinsdottir et al. (in press b), who first indicated multiple spawning origins of pelagic juvenile cod in Icelandic waters. Consequently, each year class is comprised of progeny originating from multiple spawning components, whose relative contribution varies each year dependent upon stock and environmental factors that influence dispersal and subsequent survival of the early life-history stages (Marteinsdottir et al. in press b). Incorporating spawning diversity and stock complexity into the functional stock and recruitment relationship will explain some of its inherent variability, while reducing the variability associated with biological reference limits and other management strategies that are based on this relationship (i.e. Cook 1997).

Generally, pelagic juvenile cod are distributed around the west, north, and east coasts of Iceland following spawning of adult cod from March to June. In years when the relative abundance of pelagic juvenile cod was high (i.e. 1973, 1976, 1984 and 1985), large aggregations were also found near Greenland, where they no doubt dispersed from the main spawning grounds in the south with the flow of the northern and then western branch of the Irminger Current (Malmberg et al. 1996). Pelagic juvenile cod comprising these aggregations are thought to remain in Greenland waters for several years before returning to Icelandic waters as mature individuals to spawn (Schopka 1994). In the latter years of the 0-group fish survey (1997 and 1998), when the relative abundance of pelagic juvenile cod was also high, the apparent lack of cod near Greenland was probably due to inadequate station coverage as opposed to the unlikely absence of fish (i.e. Sveinbjörnsson \& Jónsson 1998). Concurrent length, age, hatch and spawning distributions of pelagic juvenile cod from the Greenland component (Fig. 1: Region 8) with those of cod from the main spawning component (Region 1), provide strong evidence for similar spawning origins. As a result, the Greenland component provides a demographic template that can be compared to the other components (Regions 2 to 7 ) and used as a measure of natal congruity with those pelagic juvenile cod originating from the main spawning component in the south. Consequently, in any given year, significant proportions of pelagic juvenile cod found off the north and east coasts 


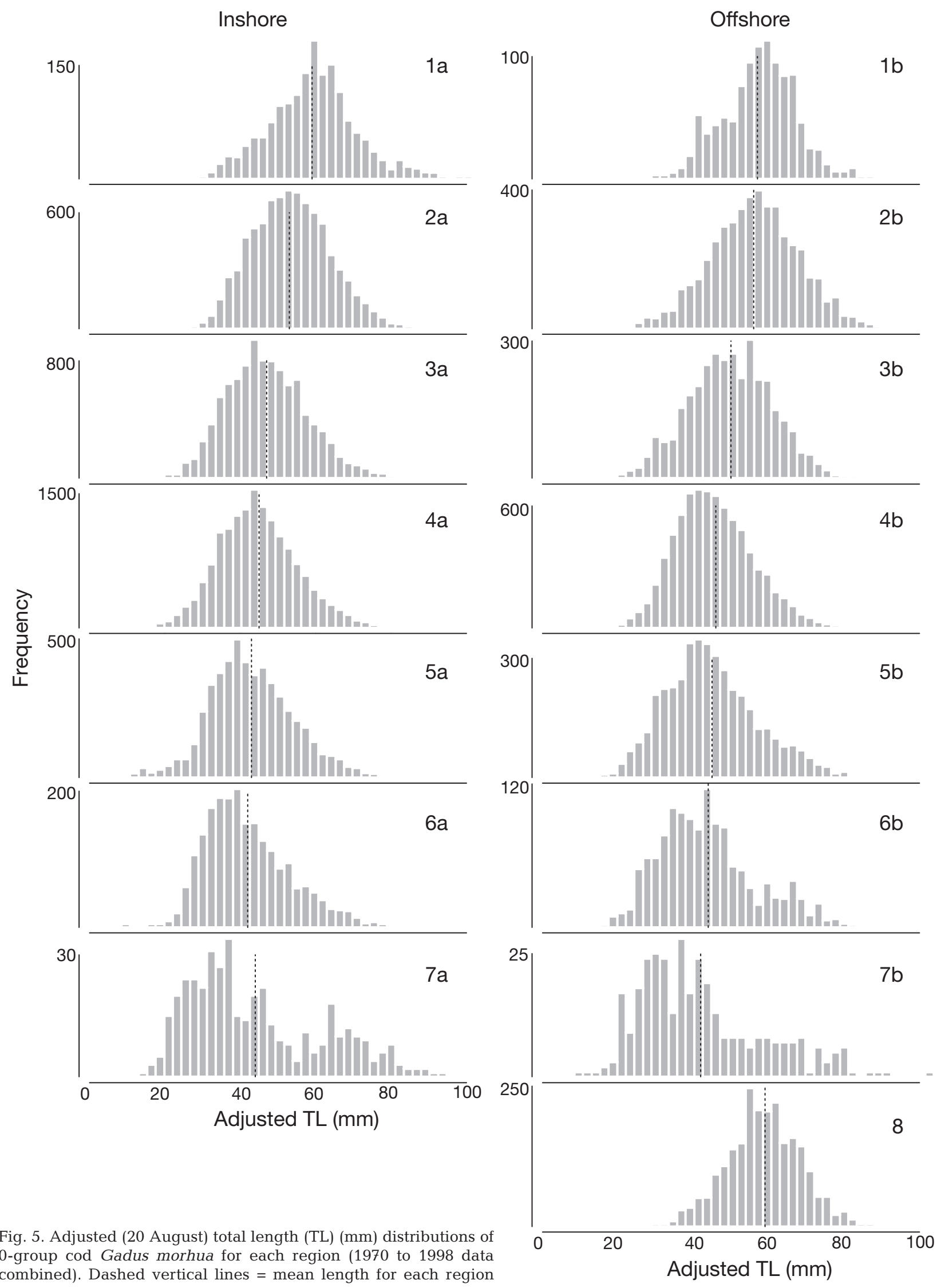



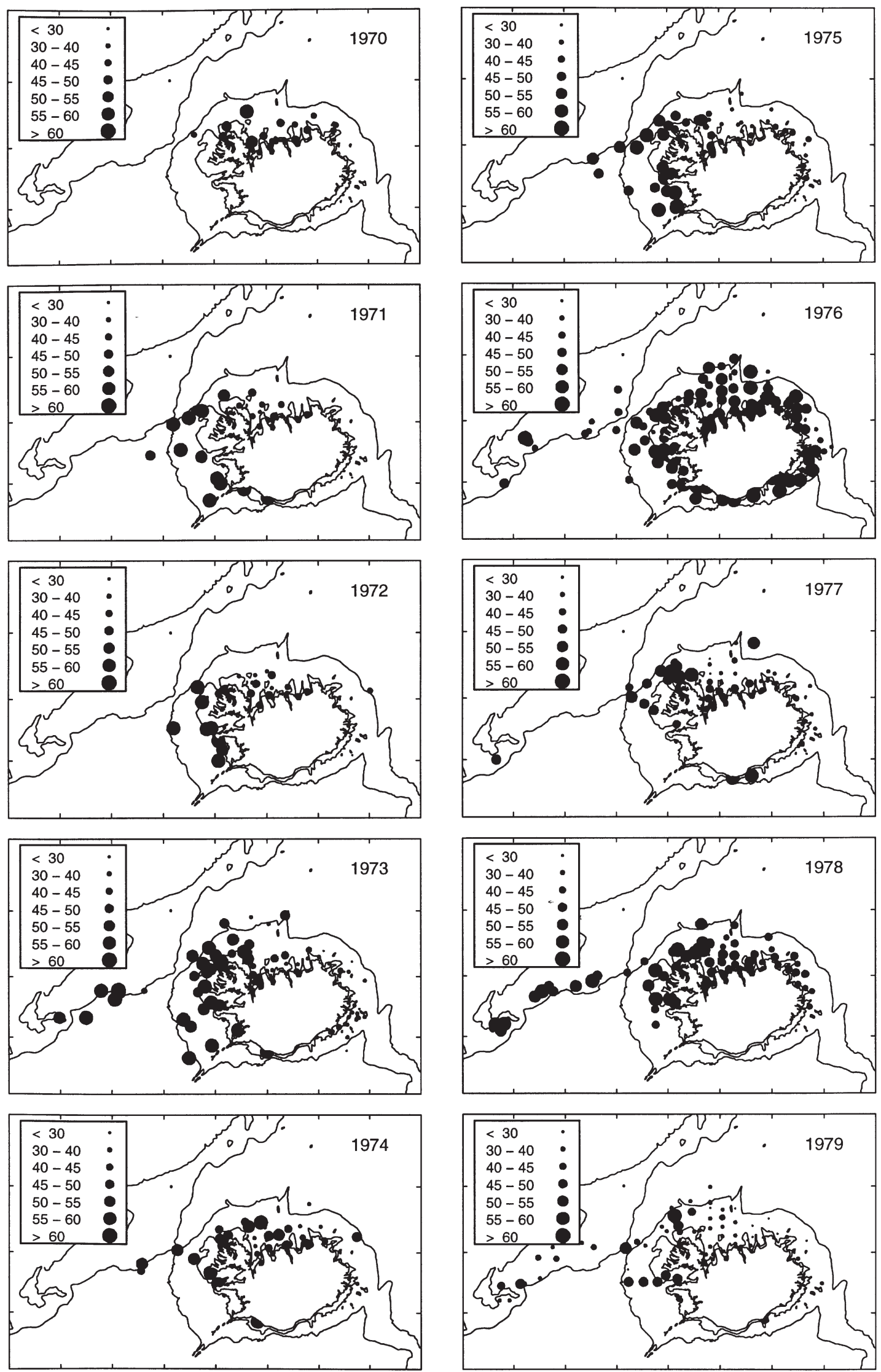

Fig. 6. (Above and 2 following pages). Annual distribution of 0-group cod Gadus morhua mean-adjusted (20 August) total lengths (mm), 1970 to 1998 

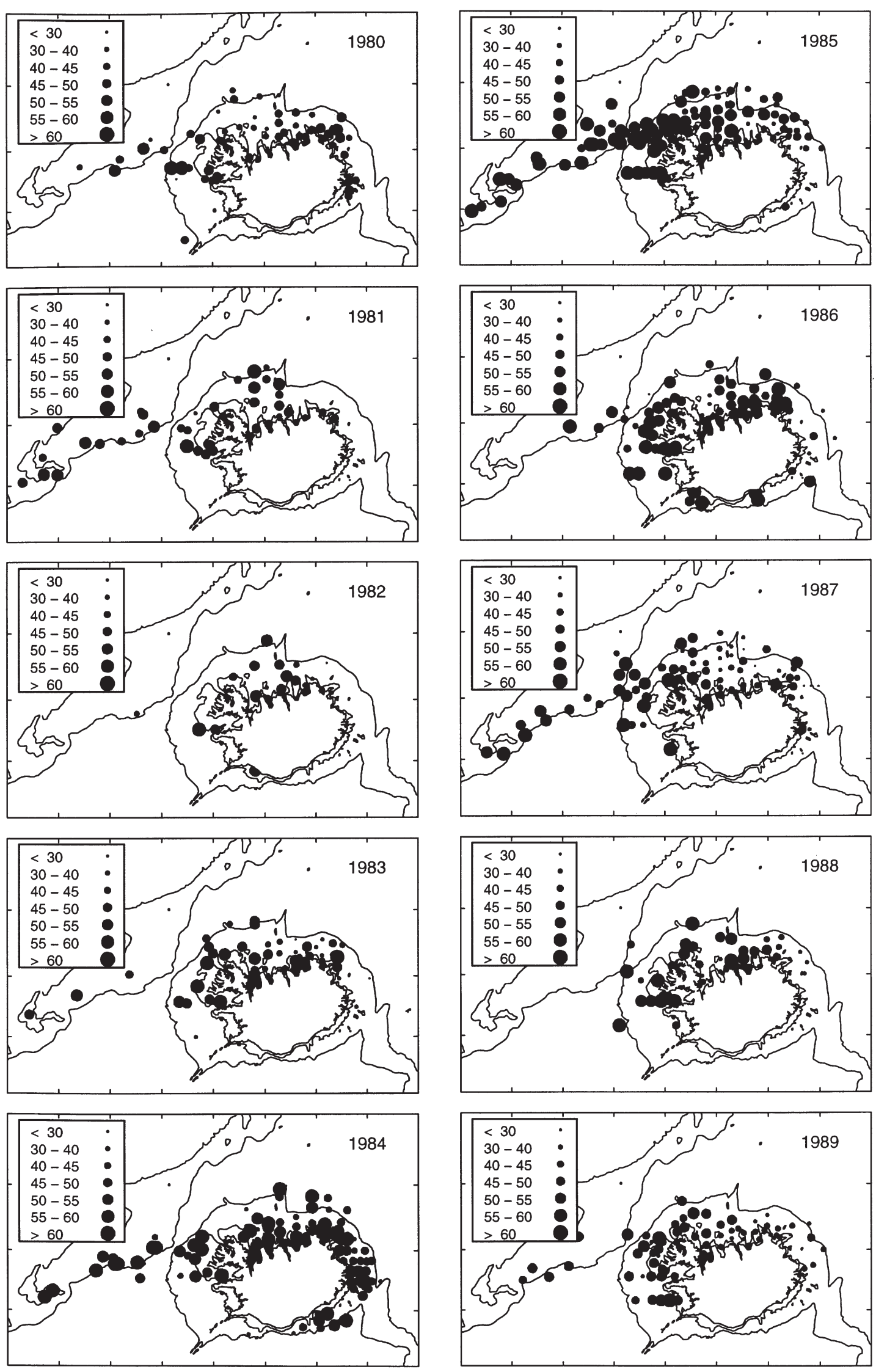

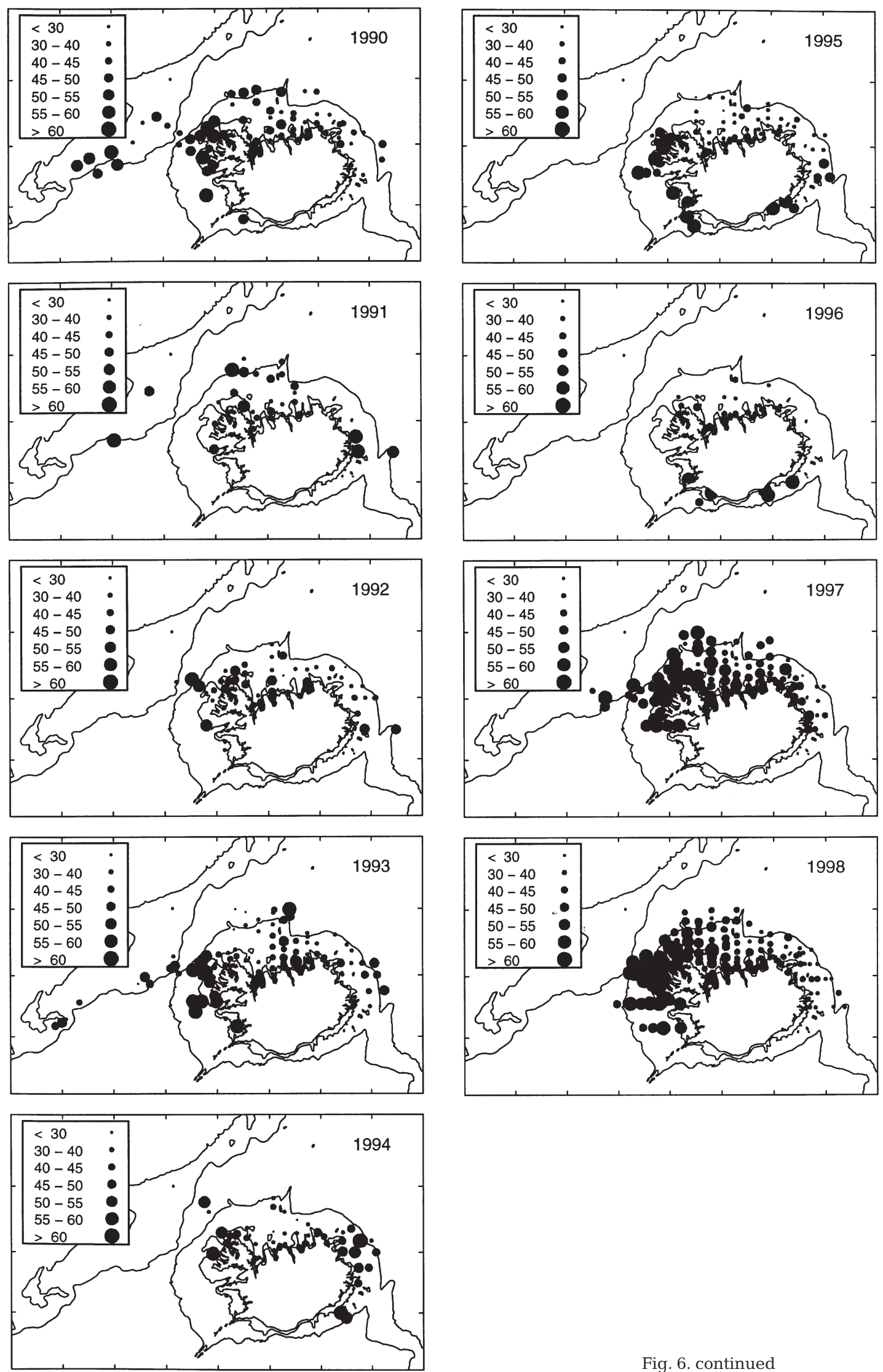

Fig. 6. continued 
Table 5. Annual mean hatch and predicted spawning DOY of 0-group cod Gadus morhua for each region (1a to 8), 1970 to 1998. na $=$ no data available

\begin{tabular}{|c|c|c|c|c|c|c|c|c|c|c|c|c|c|c|c|c|}
\hline \multirow{2}{*}{ Year } & & & & & & & & \multirow{2}{*}{$\begin{array}{l}\text { Region } \\
4 \mathrm{~b}\end{array}$} & \multirow[b]{2}{*}{$5 a$} & \multirow[b]{2}{*}{$5 b$} & \multirow[b]{2}{*}{$6 a$} & \multirow[b]{2}{*}{$6 \mathrm{~b}$} & \multirow[b]{2}{*}{$7 \mathrm{a}$} & \multirow[b]{2}{*}{$7 b$} & \multirow[b]{2}{*}{8} & Total \\
\hline & $1 \mathrm{a}$ & $1 b$ & $2 a$ & $2 b$ & $3 a$ & $3 b$ & $4 a$ & & & & & & & & & \\
\hline Mean & tchin & DOY & & & & & & & & & & & & & & \\
\hline 1970 & 177 & na & 147 & 160 & 164 & 158 & 159 & 158 & 168 & 165 & na & na & na & na & na & 157 \\
\hline 1971 & 163 & 148 & 163 & 138 & 161 & 161 & 160 & 163 & na & na & na & na & 110 & na & 143 & 159 \\
\hline 1972 & 129 & 131 & 157 & 136 & 158 & 164 & 159 & 166 & na & 164 & na & na & na & na & na & 151 \\
\hline 1973 & 135 & 139 & 140 & 138 & 165 & 134 & 179 & 163 & 183 & 181 & 174 & 178 & 174 & 180 & 132 & 163 \\
\hline 1974 & 118 & na & 144 & 138 & 156 & 148 & 153 & 163 & 155 & 170 & na & 175 & na & na & 145 & 150 \\
\hline 1975 & 135 & 144 & 145 & 138 & 164 & 148 & 176 & 173 & 172 & 168 & 165 & 172 & na & na & 141 & 163 \\
\hline 1976 & 136 & 143 & 145 & 146 & 141 & 149 & 142 & 147 & 144 & 143 & 142 & 154 & 121 & 149 & 155 & 144 \\
\hline 1977 & 151 & na & 126 & 134 & 157 & 160 & 163 & 165 & 168 & 173 & 169 & 174 & 128 & na & 155 & 157 \\
\hline 1978 & 125 & 153 & 138 & 141 & 154 & 139 & 154 & 156 & 157 & 159 & 163 & 161 & na & na & 146 & 149 \\
\hline 1979 & 145 & 150 & 170 & 169 & 178 & 180 & 182 & 178 & 187 & 191 & na & 182 & 151 & na & 161 & 177 \\
\hline 1980 & 148 & 144 & 159 & 155 & 164 & 168 & 159 & 160 & 147 & 151 & 149 & 156 & na & 156 & 145 & 157 \\
\hline 1981 & 139 & 136 & 130 & 155 & 151 & 150 & 150 & 158 & 158 & na & na & na & na & na & 143 & 143 \\
\hline 1982 & 141 & 134 & 162 & na & 154 & 151 & 153 & 156 & 165 & 186 & na & na & na & na & 160 & 158 \\
\hline 1983 & 137 & 143 & 146 & 157 & 149 & 146 & 152 & 158 & 156 & 161 & na & 181 & na & na & 150 & 152 \\
\hline 1984 & 137 & 158 & 132 & 136 & 141 & 157 & 146 & 145 & 147 & 144 & 149 & 146 & 165 & 141 & 134 & 143 \\
\hline 1985 & 118 & 137 & 138 & 126 & 148 & 146 & 162 & 156 & 163 & 159 & na & na & na & 156 & 137 & 144 \\
\hline 1986 & 126 & 137 & 142 & 146 & 148 & 169 & 151 & 153 & 153 & 150 & na & 160 & 138 & 132 & 150 & 148 \\
\hline 1987 & na & 118 & 128 & 150 & 155 & 164 & 166 & 165 & 167 & 171 & 165 & 171 & na & na & 138 & 159 \\
\hline 1988 & 151 & 139 & 131 & 146 & 162 & 146 & 160 & 148 & 167 & 160 & na & na & na & na & 153 & 154 \\
\hline 1989 & 148 & 146 & 147 & 150 & 157 & 145 & 160 & 162 & 166 & 163 & 161 & 164 & na & na & 147 & 156 \\
\hline 1990 & 153 & 139 & 141 & 149 & 151 & 152 & 160 & 159 & 166 & 165 & 171 & 168 & na & na & 146 & 157 \\
\hline 1991 & 147 & na & 159 & 157 & 167 & 164 & 169 & 163 & na & na & 122 & 135 & na & na & 136 & 165 \\
\hline 1992 & 159 & 176 & 161 & 155 & 163 & 163 & 161 & 172 & na & 173 & 171 & 151 & na & na & 171 & 164 \\
\hline 1993 & 142 & 132 & 159 & 145 & 166 & 171 & 159 & 163 & 164 & 173 & 168 & 164 & na & na & 157 & 157 \\
\hline 1994 & na & na & 165 & 182 & 180 & 180 & 176 & 188 & 169 & 166 & 155 & 159 & na & 135 & 130 & 177 \\
\hline 1995 & 154 & 128 & 162 & 181 & 170 & 171 & 166 & 166 & 168 & 174 & 180 & 150 & 126 & 146 & na & 167 \\
\hline 1996 & 108 & 158 & 151 & 169 & 159 & 168 & 158 & 170 & 174 & 178 & na & na & 117 & 97 & na & 158 \\
\hline 1997 & 130 & 141 & 140 & 146 & 153 & 149 & 157 & 153 & 159 & 162 & 159 & 166 & 187 & na & 136 & 153 \\
\hline 1998 & 133 & 132 & 144 & 143 & 161 & 151 & 163 & 160 & 170 & 168 & 176 & 175 & na & na & 128 & 157 \\
\hline Total & 137 & 140 & 146 & 141 & 157 & 152 & 160 & 159 & 163 & 160 & 164 & 161 & 161 & 164 & 139 & \\
\hline Mean & awni & Ig DO & & & & & & & & & & & & & & \\
\hline 1970 & 164 & na & 134 & 147 & 151 & 145 & 146 & 145 & 155 & 152 & na & na & na & na & na & 144 \\
\hline 1971 & 150 & 135 & 150 & 125 & 148 & 148 & 147 & 150 & na & na & na & na & 97 & na & 130 & 146 \\
\hline 1972 & 116 & 118 & 144 & 123 & 145 & 151 & 146 & 153 & na & 151 & na & na & na & na & na & 138 \\
\hline 1973 & 118 & 122 & 123 & 121 & 148 & 117 & 162 & 146 & 166 & 164 & 157 & 161 & 157 & 163 & 115 & 146 \\
\hline 1974 & 105 & na & 131 & 125 & 143 & 135 & 140 & 150 & 142 & 157 & na & 162 & na & na & 132 & 137 \\
\hline 1975 & 121 & 130 & 131 & 124 & 150 & 134 & 162 & 159 & 158 & 154 & 151 & 158 & na & na & 127 & 149 \\
\hline 1976 & 122 & 129 & 131 & 132 & 127 & 135 & 128 & 133 & 130 & 129 & 128 & 140 & 107 & 135 & 141 & 130 \\
\hline 1977 & 136 & na & 111 & 119 & 142 & 145 & 148 & 150 & 153 & 158 & 154 & 159 & 113 & na & 140 & 142 \\
\hline 1978 & 110 & 138 & 123 & 126 & 139 & 124 & 139 & 141 & 142 & 144 & 148 & 146 & na & na & 131 & 134 \\
\hline 1979 & 126 & 131 & 151 & 150 & 159 & 161 & 163 & 159 & 168 & 172 & na & 163 & 132 & na & 142 & 158 \\
\hline 1980 & 133 & 129 & 144 & 140 & 149 & 153 & 144 & 145 & 132 & 136 & 134 & 141 & na & 141 & 130 & 142 \\
\hline 1981 & 124 & 121 & 115 & 140 & 136 & 135 & 135 & 143 & 143 & na & na & na & na & na & 128 & 128 \\
\hline 1982 & 127 & 120 & 148 & na & 140 & 137 & 139 & 142 & 151 & 172 & na & na & na & na & 146 & 144 \\
\hline 1983 & 121 & 127 & 130 & 141 & 133 & 130 & 136 & 142 & 140 & 145 & na & 165 & na & na & 134 & 136 \\
\hline 1984 & 121 & 142 & 116 & 120 & 125 & 141 & 130 & 129 & 131 & 128 & 133 & 130 & 149 & 125 & 118 & 127 \\
\hline 1985 & 103 & 122 & 123 & 111 & 133 & 131 & 147 & 141 & 148 & 144 & na & na & na & 141 & 122 & 129 \\
\hline 1986 & 111 & 122 & 127 & 131 & 133 & 154 & 136 & 138 & 138 & 135 & na & 145 & 123 & 117 & 135 & 133 \\
\hline 1987 & na & 104 & 114 & 136 & 141 & 150 & 152 & 151 & 153 & 157 & 151 & 157 & na & na & 124 & 145 \\
\hline 1988 & 137 & 125 & 117 & 132 & 148 & 132 & 146 & 134 & 153 & 146 & na & na & na & na & 139 & 140 \\
\hline 1989 & 131 & 129 & 130 & 133 & 140 & 128 & 143 & 145 & 149 & 146 & 144 & 147 & na & na & 130 & 139 \\
\hline 1990 & 136 & 122 & 124 & 132 & 134 & 135 & 143 & 142 & 149 & 148 & 154 & 151 & na & na & 129 & 140 \\
\hline 1991 & 131 & na & 143 & 141 & 151 & 148 & 153 & 147 & na & na & 106 & 119 & na & na & 120 & 149 \\
\hline 1992 & 143 & 160 & 145 & 139 & 147 & 147 & 145 & 156 & na & 157 & 155 & 135 & na & na & 155 & 148 \\
\hline 1993 & 125 & 115 & 142 & 128 & 149 & 154 & 142 & 146 & 147 & 156 & 151 & 147 & na & na & 140 & 140 \\
\hline 1994 & na & na & 151 & 168 & 166 & 166 & 162 & 174 & 155 & 152 & 141 & 145 & na & 121 & 116 & 163 \\
\hline 1995 & 138 & 112 & 146 & 165 & 154 & 155 & 150 & 150 & 152 & 158 & 164 & 134 & 110 & 130 & na & 151 \\
\hline 1996 & 95 & 145 & 138 & 156 & 146 & 155 & 145 & 157 & 161 & 165 & na & na & 104 & 84 & na & 145 \\
\hline 1997 & 112 & 123 & 122 & 128 & 135 & 131 & 139 & 135 & 141 & 144 & 141 & 148 & 169 & na & 118 & 135 \\
\hline 1998 & 117 & 116 & 128 & 127 & 145 & 135 & 147 & 144 & 154 & 152 & 160 & 159 & na & na & 112 & 141 \\
\hline Total & 121 & 125 & 131 & 126 & 141 & 136 & 145 & 143 & 147 & 144 & 148 & 145 & 144 & 147 & 123 & \\
\hline
\end{tabular}


Table 6. Proportion of 0-group cod Gadus morhua in each region (1a to 8) predicted to have originated from main spawning grounds in south (Region 1) for main spawning period, 1970 to 1998. Proportions are based on number of cod spawned at later DOY than that estimated for $99 \%$ percentile (159 DOY) and $95 \%$ percentile (150 DOY). na $=$ no data available

\begin{tabular}{|c|c|c|c|c|c|c|c|c|c|c|c|c|c|c|c|c|}
\hline \multirow[t]{2}{*}{ Year } & \multicolumn{15}{|c|}{ Region } & \multirow[t]{2}{*}{ Total } \\
\hline & $1 \mathrm{a}$ & $1 b$ & $2 \mathrm{a}$ & $2 \mathrm{~b}$ & $3 a$ & $3 b$ & $4 \mathrm{a}$ & $4 \mathrm{~b}$ & $5 a$ & $5 b$ & $6 a$ & $6 b$ & $7 a$ & $7 \mathrm{~b}$ & 8 & \\
\hline \multicolumn{17}{|c|}{ 99\% percentile (159 DOY) } \\
\hline 1970 & 0.25 & na & 0.99 & 0.87 & 0.62 & 0.95 & 0.86 & 0.92 & 0.51 & 0.81 & na & na & na & na & na & 0.84 \\
\hline 1971 & 0.94 & 1.00 & 0.91 & 1.00 & 0.95 & 0.89 & 0.91 & 0.90 & na & na & na & na & 1.00 & na & 1.00 & 0.93 \\
\hline 1972 & 1.00 & 1.00 & 0.89 & 1.00 & 0.84 & 0.74 & 0.76 & 0.67 & na & 0.71 & na & na & na & na & na & 0.84 \\
\hline 1973 & 1.00 & 1.00 & 0.99 & 1.00 & 0.78 & 0.96 & 0.39 & 0.86 & 0.33 & 0.28 & 0.58 & 0.41 & 0.48 & 0.37 & 1.00 & 0.67 \\
\hline 1974 & 1.00 & na & 1.00 & 1.00 & 0.95 & 0.90 & 0.95 & 0.73 & 0.75 & 0.67 & na & 0.25 & na & na & 1.00 & 0.91 \\
\hline 1975 & 1.00 & 1.00 & 0.96 & 0.99 & 0.60 & 0.90 & 0.36 & 0.49 & 0.54 & 0.61 & 0.97 & 0.62 & na & na & 1.00 & 0.62 \\
\hline 1976 & 1.00 & 0.99 & 0.99 & 0.98 & 1.00 & 0.98 & 0.99 & 0.98 & 1.00 & 0.98 & 1.00 & 0.86 & 1.00 & 0.94 & 0.95 & 0.98 \\
\hline 1977 & 1.00 & na & 1.00 & 0.99 & 0.94 & 0.72 & 0.80 & 0.65 & 0.75 & 0.51 & 0.75 & 0.52 & 1.00 & na & 1.00 & 0.82 \\
\hline 1978 & 1.00 & 1.00 & 1.00 & 1.00 & 0.98 & 0.99 & 0.97 & 0.99 & 0.99 & 0.95 & 0.90 & 0.93 & na & na & 1.00 & 0.98 \\
\hline 1979 & 1.00 & 0.89 & 0.75 & 0.58 & 0.49 & 0.41 & 0.35 & 0.50 & 0.20 & 0.04 & na & 0.00 & 1.00 & na & 0.88 & 0.48 \\
\hline 1980 & 1.00 & 0.88 & 0.95 & 0.92 & 0.86 & 0.75 & 0.84 & 0.91 & 0.99 & 0.97 & 1.00 & 1.00 & na & 1.00 & 1.00 & 0.92 \\
\hline 1981 & 1.00 & 1.00 & 1.00 & 0.94 & 0.98 & 0.80 & 0.98 & 0.93 & 0.91 & na & na & na & na & na & 0.99 & 0.98 \\
\hline 1982 & 1.00 & 1.00 & 0.94 & na & 0.83 & 1.00 & 0.86 & 0.84 & 0.67 & 0.00 & na & na & na & na & 1.00 & 0.87 \\
\hline 1983 & 1.00 & 1.00 & 1.00 & 0.80 & 0.99 & 0.93 & 0.87 & 0.87 & 0.90 & 0.55 & na & 0.25 & na & na & 1.00 & 0.88 \\
\hline 1984 & 1.00 & 1.00 & 1.00 & 1.00 & 1.00 & 0.83 & 0.97 & 0.96 & 0.98 & 0.96 & 0.99 & 0.98 & 0.92 & 1.00 & 1.00 & 0.98 \\
\hline 1985 & 1.00 & 1.00 & 0.99 & 0.99 & 0.94 & 0.99 & 0.85 & 0.77 & 0.91 & 0.90 & na & na & na & 1.00 & 1.00 & 0.93 \\
\hline 1986 & 1.00 & 1.00 & 0.98 & 0.96 & 0.97 & 0.75 & 0.90 & 0.94 & 1.00 & 0.88 & na & 0.91 & 1.00 & 1.00 & 1.00 & 0.95 \\
\hline 1987 & na & 1.00 & 1.00 & 0.96 & 0.92 & 0.71 & 0.75 & 0.76 & 0.62 & 0.52 & 0.80 & 0.75 & na & na & 1.00 & 0.80 \\
\hline 1988 & 1.00 & 1.00 & 1.00 & 0.83 & 0.92 & 1.00 & 0.78 & 0.82 & 0.87 & 0.74 & na & na & na & na & 1.00 & 0.86 \\
\hline 1989 & 1.00 & 0.95 & 1.00 & 0.97 & 0.96 & 1.00 & 0.96 & 0.80 & 0.79 & 0.83 & 1.00 & 1.00 & na & na & 1.00 & 0.95 \\
\hline 1990 & 1.00 & 1.00 & 1.00 & 1.00 & 0.99 & 1.00 & 0.93 & 0.98 & 0.89 & 0.93 & 0.83 & 1.00 & na & na & 1.00 & 0.95 \\
\hline 1991 & 1.00 & na & 1.00 & 0.67 & 0.68 & 1.00 & 0.71 & 0.87 & na & na & 1.00 & 1.00 & na & na & 1.00 & 0.77 \\
\hline 1992 & 0.50 & 0.25 & 0.88 & 0.83 & 0.79 & 0.87 & 0.80 & 0.55 & na & 0.59 & 0.66 & 1.00 & na & na & 1.00 & 0.77 \\
\hline 1993 & 1.00 & 1.00 & 0.88 & 0.95 & 0.81 & 0.69 & 0.91 & 0.84 & 0.80 & 0.52 & 0.79 & 0.80 & na & na & 0.93 & 0.88 \\
\hline 1994 & na & na & 0.59 & 0.00 & 0.28 & 0.20 & 0.45 & 0.04 & 0.58 & 0.50 & 1.00 & 1.00 & na & 1.00 & 1.00 & 0.38 \\
\hline 1995 & 0.99 & 1.00 & 0.90 & 0.00 & 0.67 & 0.62 & 0.75 & 0.78 & 0.75 & 0.51 & 0.29 & 0.89 & 1.00 & 1.00 & na & 0.72 \\
\hline 1996 & 1.00 & 1.00 & 0.97 & 0.67 & 0.92 & 1.00 & 0.93 & 0.67 & 0.40 & 0.33 & na & na & 1.00 & 1.00 & na & 0.86 \\
\hline 1997 & 1.00 & 1.00 & 1.00 & 0.99 & 0.99 & 0.95 & 0.96 & 0.96 & 0.91 & 0.81 & 0.79 & 0.86 & 0.00 & na & 1.00 & 0.94 \\
\hline 1998 & 1.00 & 1.00 & 0.99 & 0.98 & 0.87 & 0.96 & 0.84 & 0.87 & 0.62 & 0.72 & 0.47 & 0.46 & na & na & 1.00 & 0.85 \\
\hline Total & 0.99 & 0.99 & 0.97 & 0.97 & 0.86 & 0.91 & 0.82 & 0.85 & 0.76 & 0.77 & 0.72 & 0.76 & 0.63 & 0.63 & 0.99 & \\
\hline \multicolumn{17}{|c|}{$95 \%$ percentile (150 DOY) } \\
\hline 1970 & 0.00 & na & 0.91 & 0.54 & 0.36 & 0.71 & 0.57 & 0.53 & 0.24 & 0.38 & na & na & na & na & na & 0.60 \\
\hline 1971 & 0.52 & 0.87 & 0.48 & 0.94 & 0.63 & 0.62 & 0.66 & 0.49 & na & na & na & na & 1.00 & na & 1.00 & 0.61 \\
\hline 1972 & 1.00 & 1.00 & 0.57 & 1.00 & 0.62 & 0.52 & 0.60 & 0.35 & na & 0.44 & na & na & na & na & na & 0.68 \\
\hline 1973 & 1.00 & 1.00 & 0.98 & 0.99 & 0.51 & 0.92 & 0.20 & 0.65 & 0.18 & 0.16 & 0.24 & 0.12 & 0.29 & 0.19 & 1.00 & 0.51 \\
\hline 1974 & 1.00 & na & 1.00 & 1.00 & 0.63 & 0.82 & 0.82 & 0.42 & 0.50 & 0.08 & na & 0.00 & na & na & 1.00 & 0.78 \\
\hline 1975 & 1.00 & 1.00 & 0.87 & 0.94 & 0.44 & 0.78 & 0.18 & 0.18 & 0.26 & 0.38 & 0.49 & 0.23 & na & na & 0.98 & 0.45 \\
\hline 1976 & 1.00 & 0.96 & 0.96 & 0.91 & 0.99 & 0.89 & 0.96 & 0.89 & 0.95 & 0.92 & 0.96 & 0.66 & 1.00 & 0.67 & 0.79 & 0.93 \\
\hline 1977 & 1.00 & na & 1.00 & 0.95 & 0.78 & 0.63 & 0.52 & 0.41 & 0.30 & 0.26 & 0.31 & 0.09 & 1.00 & na & 0.80 & 0.60 \\
\hline 1978 & 1.00 & 1.00 & 0.99 & 0.98 & 0.80 & 0.97 & 0.84 & 0.82 & 0.84 & 0.82 & 0.67 & 0.73 & na & na & 0.98 & 0.88 \\
\hline 1979 & 1.00 & 0.89 & 0.39 & 0.34 & 0.19 & 0.11 & 0.07 & 0.26 & 0.00 & 0.00 & na & 0.00 & 1.00 & na & 0.64 & 0.22 \\
\hline 1980 & 1.00 & 0.85 & 0.70 & 0.79 & 0.55 & 0.31 & 0.77 & 0.66 & 0.94 & 0.86 & 0.93 & 0.91 & na & 0.94 & 0.94 & 0.75 \\
\hline 1981 & 0.98 & 1.00 & 1.00 & 0.88 & 0.91 & 0.80 & 0.89 & 0.71 & 0.74 & na & na & na & na & na & 0.97 & 0.94 \\
\hline 1982 & 1.00 & 1.00 & 0.66 & na & 0.61 & 1.00 & 0.68 & 0.68 & 0.40 & 0.00 & na & na & na & na & 1.00 & 0.64 \\
\hline 1983 & 0.98 & 0.88 & 0.95 & 0.80 & 0.89 & 0.93 & 0.75 & 0.65 & 0.73 & 0.48 & na & 0.25 & na & na & 1.00 & 0.78 \\
\hline 1984 & 0.96 & 0.75 & 1.00 & 0.96 & 0.99 & 0.67 & 0.89 & 0.90 & 0.85 & 0.89 & 0.87 & 0.87 & 0.31 & 0.90 & 1.00 & 0.92 \\
\hline 1985 & 0.98 & 1.00 & 0.92 & 0.95 & 0.83 & 0.91 & 0.60 & 0.63 & 0.48 & 0.60 & na & na & na & 1.00 & 0.98 & 0.80 \\
\hline 1986 & 1.00 & 1.00 & 0.95 & 0.93 & 0.90 & 0.25 & 0.80 & 0.83 & 1.00 & 0.75 & na & 0.70 & 1.00 & 1.00 & 0.97 & 0.86 \\
\hline 1987 & na & 1.00 & 1.00 & 0.86 & 0.73 & 0.46 & 0.43 & 0.49 & 0.44 & 0.39 & 0.40 & 0.00 & na & na & 1.00 & 0.59 \\
\hline 1988 & 0.69 & 1.00 & 1.00 & 0.83 & 0.46 & 1.00 & 0.48 & 0.82 & 0.47 & 0.42 & na & na & na & na & 1.00 & 0.62 \\
\hline 1989 & 0.96 & 0.95 & 0.94 & 0.92 & 0.84 & 1.00 & 0.79 & 0.60 & 0.51 & 0.70 & 0.50 & 1.00 & na & na & 1.00 & 0.82 \\
\hline 1990 & 1.00 & 1.00 & 1.00 & 1.00 & 0.95 & 1.00 & 0.68 & 0.76 & 0.53 & 0.73 & 0.29 & 0.50 & na & na & 0.97 & 0.77 \\
\hline 1991 & 1.00 & na & 0.67 & 0.67 & 0.42 & 0.50 & 0.35 & 0.57 & na & na & 1.00 & 1.00 & na & na & 1.00 & 0.47 \\
\hline 1992 & 0.50 & 0.00 & 0.60 & 0.66 & 0.55 & 0.62 & 0.52 & 0.29 & na & 0.24 & 0.32 & 1.00 & na & na & 0.00 & 0.50 \\
\hline 1993 & 1.00 & 1.00 & 0.70 & 0.87 & 0.51 & 0.38 & 0.72 & 0.58 & 0.55 & 0.24 & 0.34 & 0.60 & na & na & 0.81 & 0.70 \\
\hline 1994 & na & na & 0.39 & 0.00 & 0.12 & 0.00 & 0.26 & 0.00 & 0.25 & 0.44 & 0.75 & 1.00 & na & 1.00 & 1.00 & 0.21 \\
\hline 1995 & 0.91 & 1.00 & 0.58 & 0.00 & 0.34 & 0.31 & 0.49 & 0.49 & 0.41 & 0.25 & 0.07 & 0.89 & 1.00 & 1.00 & na & 0.45 \\
\hline 1996 & 1.00 & 1.00 & 0.91 & 0.33 & 0.74 & 0.00 & 0.71 & 0.22 & 0.06 & 0.00 & na & na & 1.00 & 1.00 & na & 0.65 \\
\hline 1997 & 1.00 & 1.00 & 0.99 & 0.95 & 0.89 & 0.85 & 0.79 & 0.83 & 0.72 & 0.66 & 0.68 & 0.59 & 0.00 & na & 1.00 & 0.83 \\
\hline 1998 & 0.99 & 1.00 & 0.95 & 0.92 & 0.63 & 0.85 & 0.57 & 0.64 & 0.35 & 0.46 & 0.20 & 0.15 & na & na & 1.00 & 0.67 \\
\hline Total & 0.95 & 0.96 & 0.88 & 0.90 & 0.70 & 0.78 & 0.62 & 0.65 & 0.55 & 0.60 & 0.49 & 0.55 & 0.48 & 0.47 & 0.97 & \\
\hline
\end{tabular}




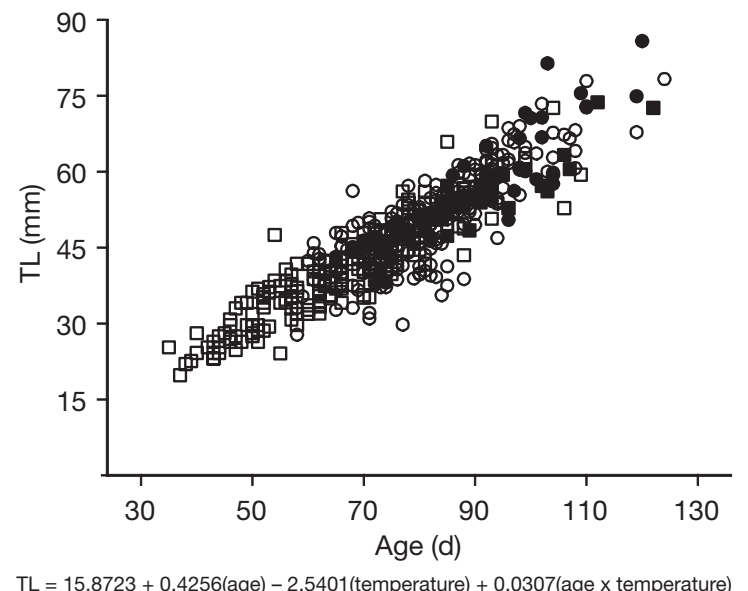

Fig. 7. Total length (TL) (mm)/age (d) relationship of 0-group cod Gadus morhua used to reconstruct historical age at capture for determination of hatching day and spawning origin. Growth relationship based on Marteinsdottir et al. (in press b) for combined $1995(\square, \mathbf{\square})$ and $1997(0, \bullet)$ data for northern [Regions 2a to 6a: $(\square, 0)]$ and southern [Region 1a: $(\mathbf{\bullet}, \bullet)]$ areas

appear to have originated from spawning components other than those of the main spawning component in the south.

In contrast to the expected dispersal patterns of the coastal and Irminger currents (Malmberg et al. 1996), the clockwise demographic gradient of pelagic juvenile cod from the west to the east coasts, with progressively decreasing length and age distributions, has previously been considered to be the result of temperature-induced growth and/or incubation differences (Astthorsson et al. 1994, Marteinsdottir et al. in press b). However, although there are distinct temperature differences between waters off the north and south coasts of Iceland (Fig. 2, and Malmberg et al. 1996), pelagic juvenile cod from the different regions appear to grow at similar rates (Fig. 7, and Marteinsdottir et al. in press b). Certainly, distinct differences in incubation temperatures would prevail between those cod spawned in waters off the north and east coasts and those cod spawned on the main spawning grounds in the south, but is in itself implies the existence of differential spawning components. Those pelagic juvenile cod spawned in the colder waters off the north and east coasts would be assumed to incubate for longer periods, with spawning and subsequent hatching occurring later than in those cod spawned on the main spawning grounds in the south. Our results supported these assumptions, with smaller localized spawning occurring within fjords and inshore waters off the north and east coasts of Iceland. Similarly, Suthers \& Sundby (1993) indicated that regions of later-localized spawning were responsible for smaller pelagic juve- nile cod than those found near the main spawning grounds off Norway. Spawning of cod has also been reported throughout inshore and offshore waters all around Iceland (Sæmundsson 1924, Jónsson 1982, Marteinsdottir et al. in press a,b). Moreover, results of a mid-summer ichthyoplankton survey conducted in 1998 found large numbers of newly hatched larvae in several in-fjord areas west and north of the country (Marteinsdottir et al. unpubl. data).

Differential spawning components in regions other than the main spawning grounds in the south have been suggested previously, but have always been considered to be insignificant (Sæmundsson 1924, Jónsson 1982), and the relative proportions of the different components have never been estimated. In contrast, our study, one of the first to attempt an historical reconstruction of pelagic juvenile-cod spawning-distributions, has provided evidence for differential spawning components and estimated the relative proportions of the different regional spawning components compared to the main spawning component in the south (Table 6, Fig. 11). These proportions, however, may have been overestimated if egg drift extended through the colder waters off the northwest coast, which would delay hatching but which was not accounted for in our calculations. Future studies need to collect independent evidence of spawning times and locations around the country in order to confirm our estimates of relative proportions of pelagic juvenile cod originating from the different regional spawning components. In any given year, the relative proportions of pelagic juvenile cod originating from the different regional spawning components fluctuates widely, most likely in response to the inflow of Atlantic water from the main spawning grounds in the south to the North Icelandic shelf. Considerable variation in the Atlantic inflow to the North Icelandic shelf was demonstrated between 1980 and 1990 (Malmberg \& Kristmannsson 1992, Kristmannsson 1998), while more recently satellite-tracked drifters have also shown considerable inter-annual variation in the strength of the inflow (Valdimarsson \& Malmberg 1999). Undoubtedly, dispersal and the resultant distribution of cod early life-history stages fluctuates each year, partly in response to variable oceanographic conditions (Anderson \& Dalley 1997). Future studies need to examine the strength and timing of the Atlantic inflow on an annual basis relative to the proportions of pelagic juvenile cod originating from the different spawning components. In addition, variable stock size and mortality rates of pelagic juvenile cod originating from the different spawning components each year, dependent on temperature and other environmental factors, may also be responsible.

Variable mortality rates of progeny originating from the different spawning components most likely also 


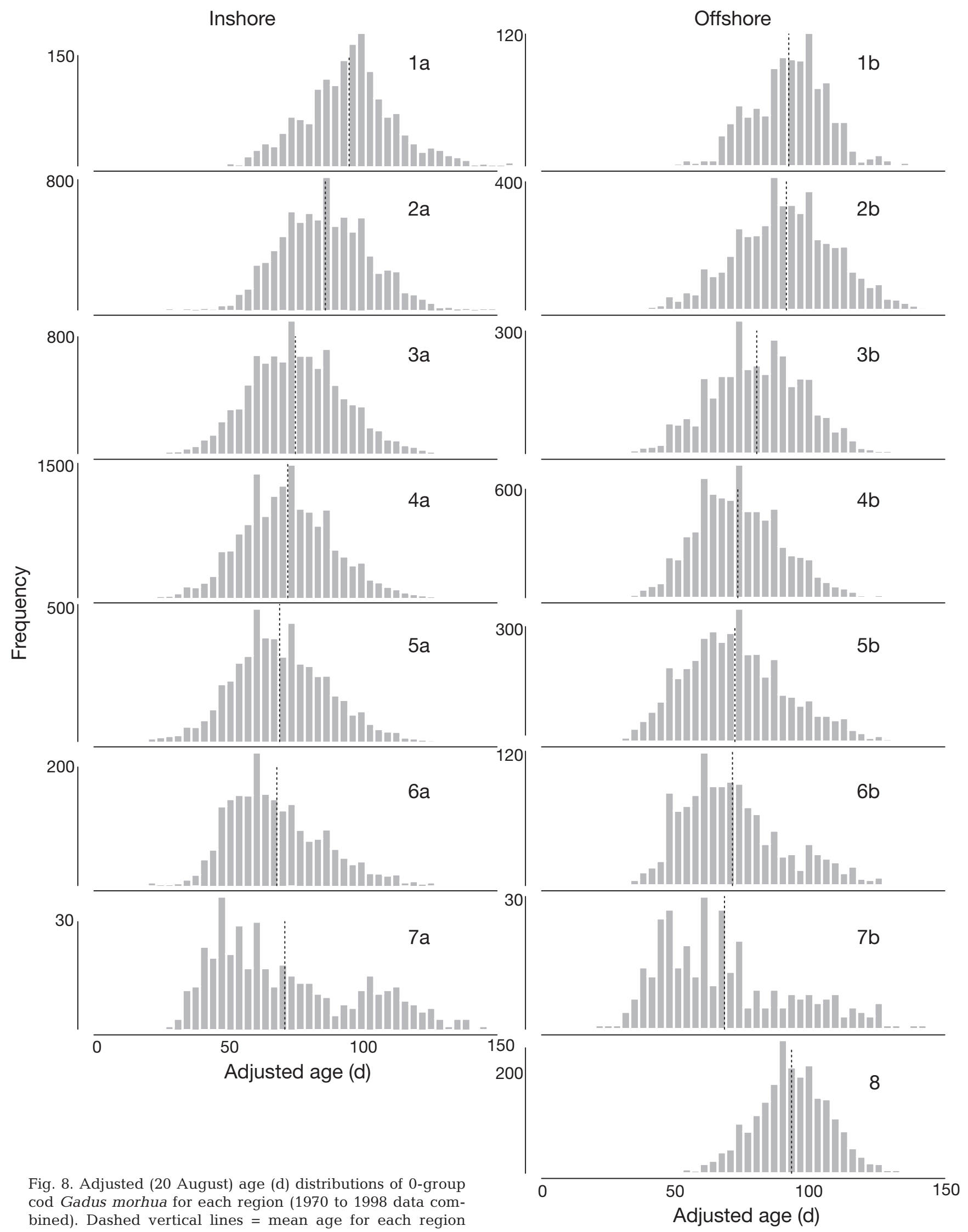




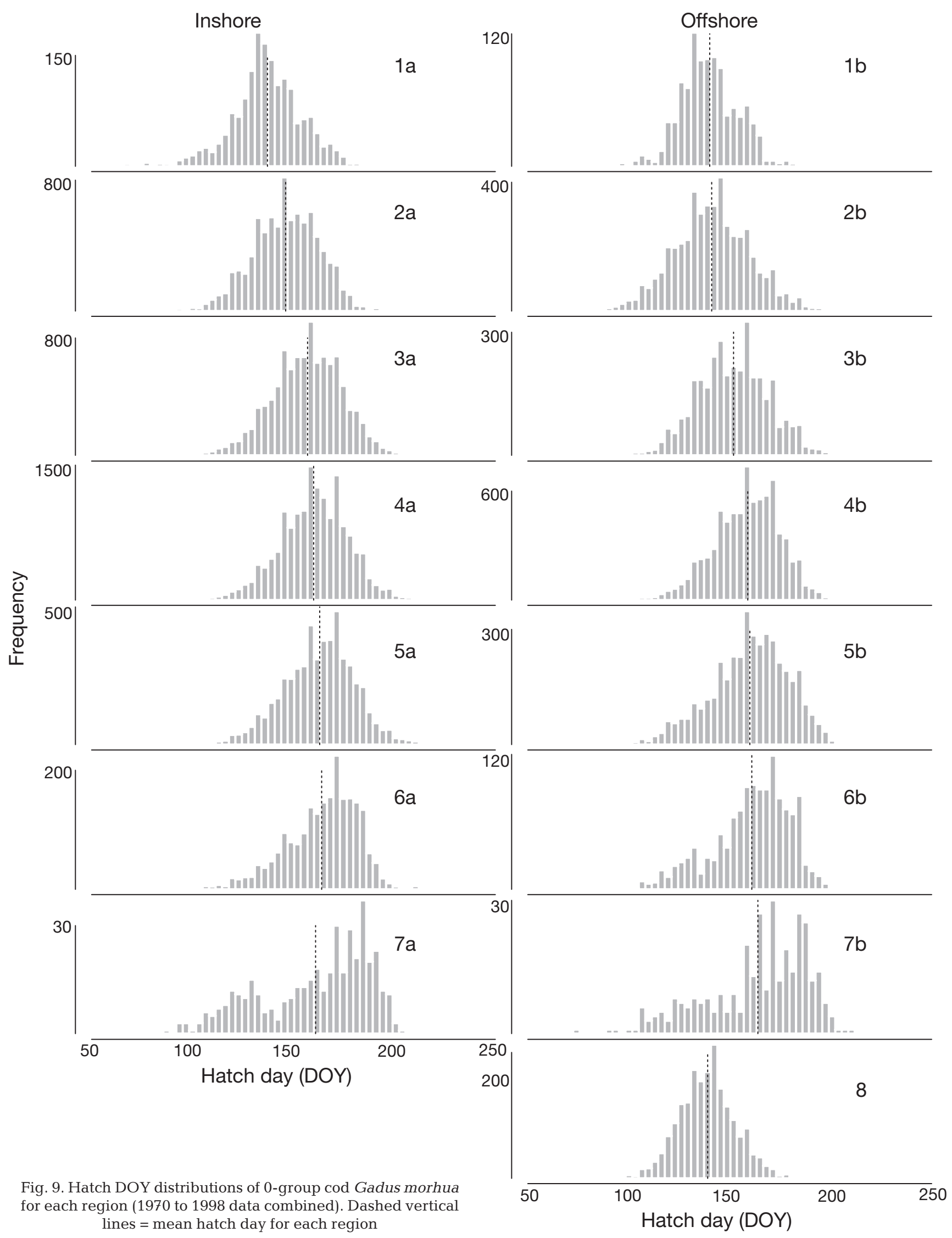




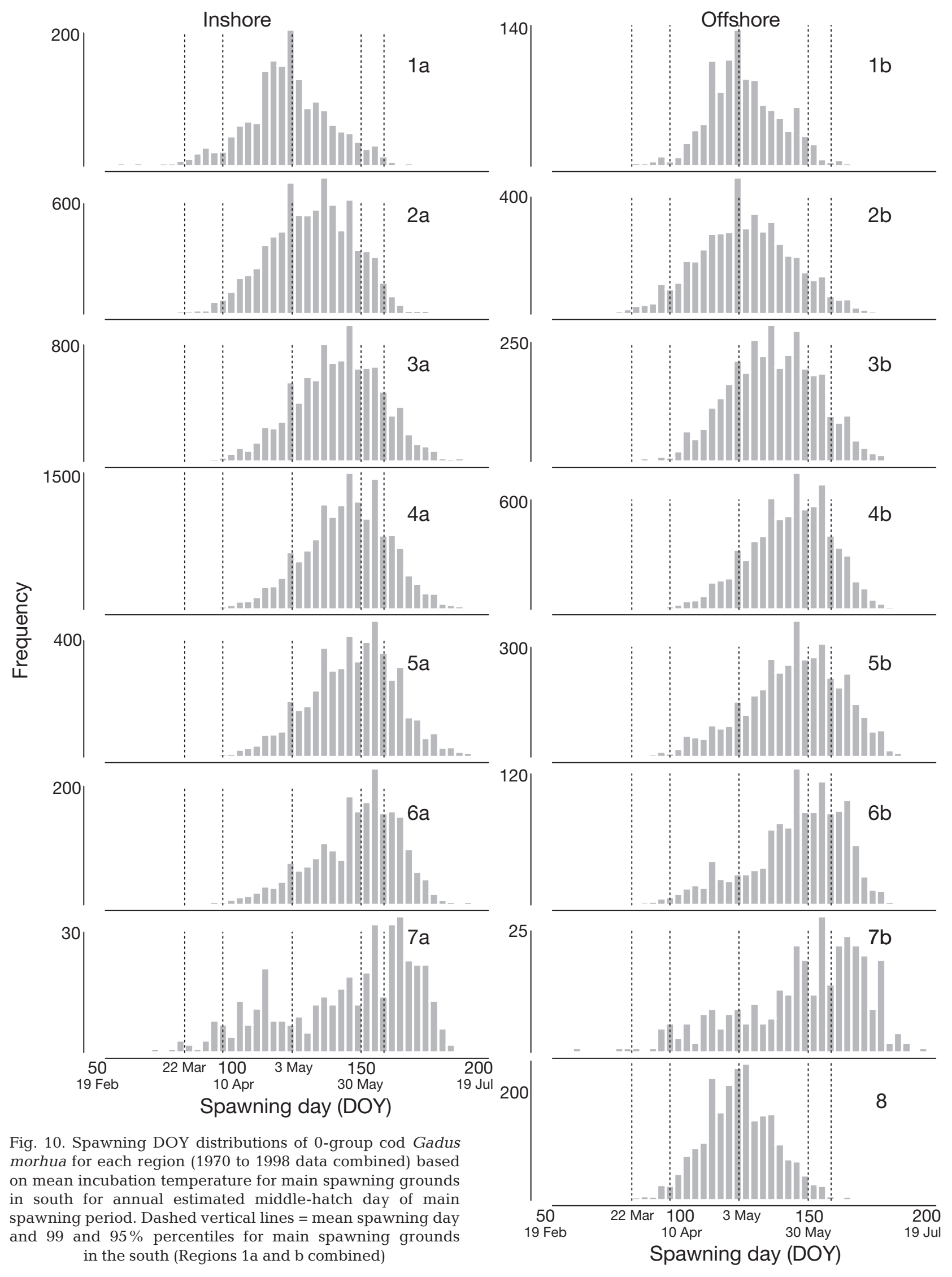



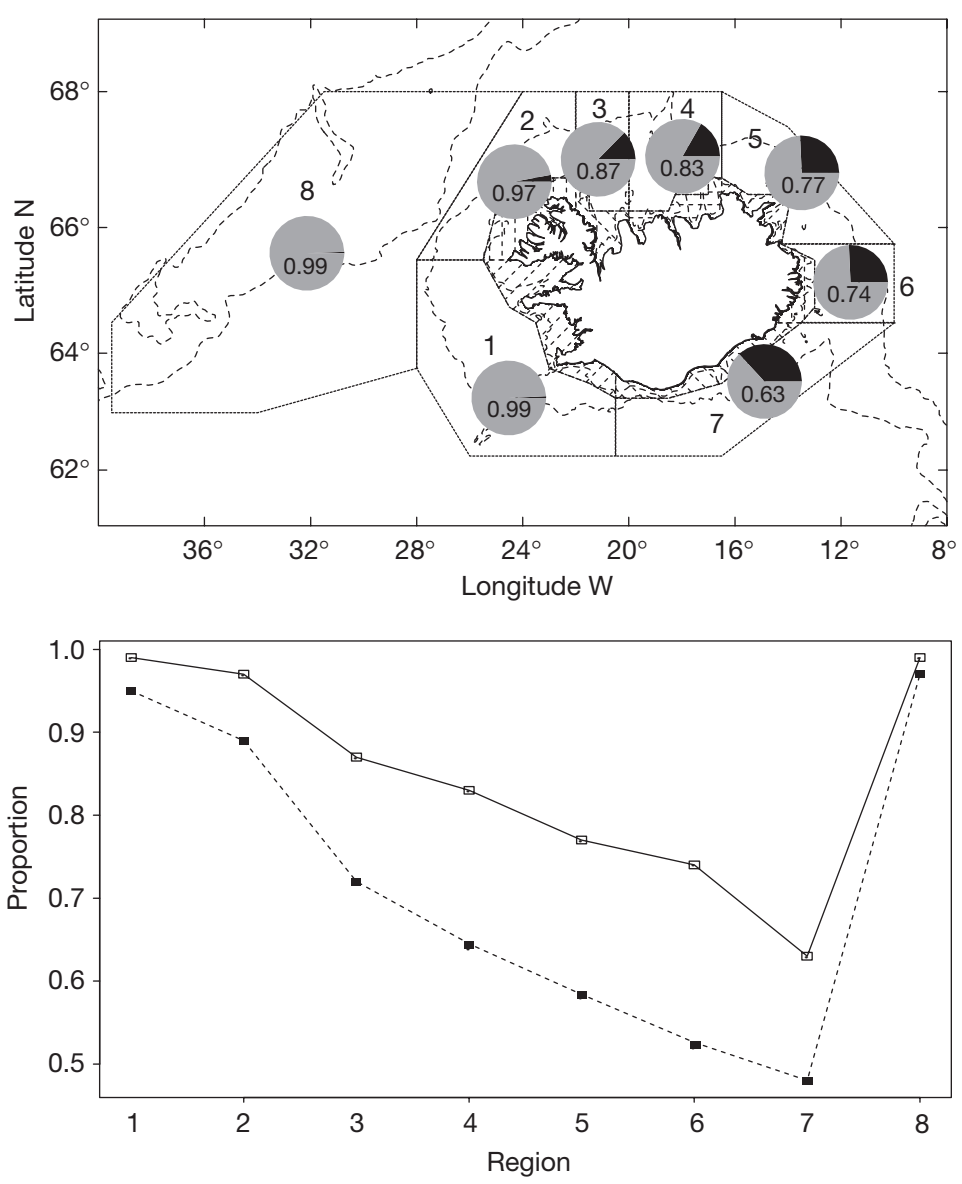

Fig. 11. Proportion of 0-group cod Gadus morhua in each region (inshore and offshore combined) predicted to have originated from main spawning grounds in south (Region 1) for main spawning period (1970 to 1998 data combined). Proportions are based on number of cod spawned at a later DOY than that estimated for $99 \%$ percentile (159 DOY, pie graphs and continuous line) and 95\% percentile (150 DOY, dashed line)

on the spawning grounds. Hutchings \& Myers (1994) postulated that spawning distributions can be influenced by low ocean temperatures acting as thermal barriers to migrating cod and as an energetic constraint to vitellogenesis. Similarly, DeYoung \& Rose (1993) suggested that spawning of adult cod can fluctuate temporally and spatially during years of low ocean temperatures, influencing the survival of their progeny through reduced opportunites to settle in favourable habitats. Consequently, constricted spawning distributions due to environmental constraints or reduced spawning biomass would invariably result in reduced opportunities for optimal survival conditions of pelagic eggs and larvae, and subsequent settlement of demersal juveniles and recruitment to the spawning stock.

Spawning diversity, or multiple spawning components, are important for successful recruitment and year-class strength as they disperse the mortality risk of early life history stages on both a temporal and spatial basis (Marteinsdottir et al. in press b). This is particularly important for the larval stage, as it is considered to be the principal determinant of year-class strength (Cushing 1969, 1990, Campana et al. 1989, Sundby et al. 1989, Mertz \& Myers 1994). Spawning diversity in a population increases the temporal and spatial range over which progeny originate, thereby enhancing, with favourable environmental conditions, their survival by decreasing the potential for mismatch (Cushing 1990, Mertz \& Myers 1994) while simultaneously increasing the potential for retention or

explains some of the inter-annual variation we observed in the abundance indices of pelagic juvenile cod (Fig. 4) and subsequent year-class strength and recruitment at older ages. Generally, progeny originating from the main spawning component in the south were larger and older than those in the north and east and, hence, may have a greater probability of survival than the smaller and younger cod (Marteinsdottir et al. in press b). Larger size at hatching and faster growth enhances the probability of survival by reducing the critical period of larvae when they are vulnerable to predation, while simultaneously increasing their ability to feed (Campana 1996, Meekan and Fortier 1996, Marteinsdottir and Steinarsson 1998). Alternatively, inter-annual variations in yearclass strength may be due to the actual spawning distributions of adult cod, mediated by temperature shifts dispersal to favourable nursery grounds and habitats (Sinclair 1988). By chance alone, a more abundant, dispersed stock, with multiple spawning components contributing to the overall recruitment and replenishment of a stock is more likely to spawn in areas providing optimal environmental conditions for survival of progeny than a single, isolated spawning stock (DeYoung \& Rose 1993). Diversity in spawning time with multiple spawning components may be a favoured strategy within the Icelandic cod stock to counter years in which variable environmental conditions exist throughout the geographic range of the population that would influence progeny survival.

Hence, our study may provide a more accurate representation of spawning and spatial stock structure than has previously been postulated for the Icelandic cod stock, while providing insights into the impor- 
tance of spawning diversity to variable recruitment levels and year-class strength. Incorporating spawning diversity and stock complexity into stock and recruitment relationships will assist in understanding variations in year-class strength. Pelagic juvenileabundance indices have been used to predict yearclass strength and subsequent recruitment at older ages (Sundby et al. 1989, Astthorsson et al. 1994, Anderson \& Dalley 1997), but often have poor predictive capabilities because of the inherent variability in these relationships. Accounting for factors that contribute to this inherent variability will undoubtedly improve our ability to predict recruitment overfishing and estimate minimum stock sizes, as has been done for age diversity in spawning stocks (Marteinsdottir \& Thorarinsson 1998). Likewise, by incorporating spawning diversity, our ability to predict year-class strength and subsequent recruitment events will no doubt also improve. Future studies into recruitment need to consider the relative proportions of cod originating from spawning components other than those of the traditionally accepted main spawning components, particularly as the ecological significance of the smaller spawning components are not known. Furthermore, the number of spawning components necessary for ensuring stock viability in all environmental conditions, and the significance of biodiversity to stock sustainability are also not known (Stephenson 1999). However, similar to our study, Hutchings et al. (1993) suggested that inshore spawning components of Atlantic cod may have provided a considerably larger contribution to recruitment than had previously been accepted in the northwest Atlantic. Moreover, it must be remembered that the proportions we estimated for Icelandic cod may have been minimum estimates, as they were based on spawning distributions later than that estimated for the 99 and $95 \%$ percentiles of the main spawning component. Certainly, spawning off the north and east coasts may have occurred earlier than the period estimated for these percentiles, resulting in even greater proportions of pelagic juvenile cod originating from spawning components other than the traditionally accepted main spawning component in the south.

Acknowledgements. Our thanks to Sveinn Sveinbjornsson and Vilhelmina Jakobsson for access to the 0-group data; Björn Gunnarsson, Iain Suthers and Adalbjörg Jónsdottir for aging of samples; Magnús Danielsen for assistance with temperature data; Hédinn Valdimarsson for discussions on oceanographic conditions; and 5 anonymous reviewers for their constructive comments. This study was part of the EU funded project, FAIR-PL98-4122, 'An operational model of the effects of stock structure and spatio-temporal factors on recruitment (STEREO)', and was supported by the Ministry of Fisheries.

\section{LITERATURE CITED}

Anderson JT, Dalley EL (1997) Spawning and year-class strength of northern cod (Gadus morhua) as measured by pelagic juvenile cod surveys, 1991-1994. Can J Fish Aquat Sci 54(Suppl 1):158-167

Anderson JT, Dalley EL, Carscadden JE (1995) Abundance and distribution of pelagic 0-group cod (Gadus morhua) in Newfoundland waters: inshore versus offshore. Can J Fish Aquat Sci 52:115-125

Anonymous (1999) Environmental conditions in Icelandic waters 1997 and 1998. Hafrannsóknastofnun Fjölrit 73: $1-48$

Astthorsson OS, Gislason A, Gudmundsdottir A (1994) Distribution, abundance, and length of pelagic juvenile cod in Icelandic waters in relation to environmental conditions. ICES Mar Sci Symp (Act Symp) 198:529-541

Baldursson FM, Daníelsson Á, Stefánsson G (1996) On the rational utilization of the Icelandic cod stock. ICES J Mar Sci 53:643-658

Begg GA, Friedland KD, Pearce JB (1999) Stock identification and its role in stock assessment and fisheries management-an overview. Fish Res 43:1-8

Beverton RJH, Holt SJ (1957) On the dynamics of exploited fish populations. Fish Investig Ser II Lond 19

Bogstad B, Lilly GR, Mehl S, Palsson OK, Stefansson G (1994) Cannibalism and year-class strength in Atlantic cod (Gadus morhua L.) in Arcto-boreal ecosystems (Barents Sea, Iceland and eastern Newfoundland). ICES Mar Sci Symp (Act Symp) 198:576-599

Campana SE (1996) Year-class strength and growth rate in young Atlantic cod Gadus morhua. Mar Ecol Prog Ser 135: $21-26$

Campana SE, Hurley PCF (1989) An age- and temperaturemediated growth model for cod (Gadus morhua) and haddock (Melanogrammus aeglefinus) larvae in the Gulf of Maine. Can J Fish Aquat Sci 46:603-613

Campana SE, Jones CM (1992) Analysis of otolith microstructure data. In: Stevenson DK, Campana SE (eds) Otolith microstructure examination and analysis. Can Spec Publ Fish Aquat Sci 117:73-100

Campana SE, Frank KT, Hurley PCF, Koeller PA, Page FH, Smith PC (1989) Survival and abundance of young Atlantic cod (Gadus morhua) and haddock (Melanogrammus aeglefinus) as indicators of year class strength. Can J Fish Aquat Sci 46(Suppl 1):171-182

Cook RM (1997) The application of a sustainability criterion to demersal stocks in the ICES area. ICES CM V:7

Cushing DH (1969) The regularity of the spawning season of some fishes. J Cons Int Explor Mer 33:81-97

Cushing DH (1971) The dependence of recruitment on parent stock in different groups of fishes. J Cons Int Explor Mer 33:340-362

Cushing DH (1990) Plankton production and year-class strength in fish populations: an update of the match/ mismatch hypothesis. Adv Mar Biol 26:249-293

Dalley EL, Anderson JT (1997) Age-dependent distribution of demersal juvenile Atlantic cod (Gadus morhua) in inshore/ offshore northeast Newfoundland. Can J Fish Aquat Sci 54(Suppl 1):168-176

DeYoung B, Rose GA (1993) On recruitment and distribution of Atlantic cod (Gadus morhua) off Newfoundland. Can J Fish Aquat Sci 50:2729-2741

Fogarty MJ (1993) Recruitment in randomly varying environments. ICES J Mar Sci 50:247-260

Fridgeirsson E (1984) Cod larvae sampling with a large pump off SW-Iceland. Flödevigen Rapp 1:317-333 
Helgason V, Sveinbjörnsson S (1987) Revised indices of cod abundance in 0-group surveys in the Iceland-East Greenland area in 1970-1986. ICES CM G:59

Hurley PCF, Campana SE (1989) The distribution and abundance of haddock (Melanogrammus aeglefinus) and Atlantic cod (Gadus morhua) eggs and larvae in the waters of southwestern Nova Scotia. Can J Fish Aquat Sci 46 (Suppl 1):103-112

Hutchings JA, Myers RA (1994) Timing of cod reproduction: interannual variability and the influence of temperature. Mar Ecol Prog Ser 108:21-31

Hutchings JA, Myers RA, Lilly GR (1993) Geographic variation in the spawning of Atlantic cod, Gadus morhua, in the northwest Atlantic. Can J Fish Aquat Sci 50:2457-2467

Jakobsen T (1996) The relationship between spawning stock and recruitment for Atlantic cod stocks. ICES CM G:15

Jakupsstovu SH, Reinert J (1994) Fluctuations in the Faroe Plateau cod stock. ICES Mar Sci Symp (Act Symp) 198: $194-211$

Jónsson E (1982) A survey of spawning and reproduction of the Icelandic cod. Rit Fiskideild 6:1-45

Kristmannsson SS (1998) Flow of Atlantic water into the northern Icelandic shelf area, 1985-1989. North AtlanticNorwegian Sea Exchanges: ICES NANSEN project. ICES Co-op Res Rep 225:124-135

Malmberg SA, Kristmannsson SS (1992) Hydrographic conditions in Icelandic waters, 1980-1989. ICES Mar Sci Symp (Act Symp) 195:76-92

Malmberg SA, Valdimarsson H, Mortensen J (1996) Longtime series in Icelandic waters in relation to physical variability in the northern North Atlantic. NAFO Sci Coun Stud 24:69-80

Marshall CT, Kjesbu OS, Yaragina NA, Solemdal P, Ulltang Ø (1998) Is spawner biomass a sensitive measure of the reproductive and recruitment potential of Northeast Arctic cod? Can J Fish Aquat Sci 55:1766-1783

Marteinsdottir G, Petursdottir G (1995) Spatial and temporal variation in reproduction of Icelandic cod at Selvogsbanki and nearby coastal areas. ICES C G:15

Marteinsdottir G, Steinarsson A (1998) Maternal influence on the size and viability of Iceland cod Gadus morhua eggs and larvae. J Fish Biol 52:1241-1258

Marteinsdottir G, Thorarinsson K (1998) Improving the stockrecruitment relationship in Icelandic cod (Gadus morhua) by including age diversity of spawners. Can J Fish Aquat Sci 55:1372-1377

Marteinsdottir G, Gudmundsdottir A, Porsteinsson V, Stefánsson G (in press a) Spatial variation in abundance, size composition and viable egg production of spawning cod (Gadus morhua L.) in Icelandic waters. ICES J Mar Sci 57

Marteinsdottir G, Gunnarsson B, Suthers IM (in press b) Spatial variation in hatch date distributions and origin of pelagic juvenile cod in Icelandic waters. ICES J Mar Sci 58

Meekan MG, Fortier L (1996) Selection for fast growth during the larval life of Atlantic cod Gadus morhua on the Scotian Shelf. Mar Ecol Prog Ser 137:25-37

Editorial responsibility: Otto Kinne (Editor), Oldendorf/Luhe, Germany
Mertz G, Myers RA (1994) Match/mismatch predictions of spawning duration versus recruitment variability. Fish Oceanogr 3:236-245

Myers RA, Barrowman NJ (1996) Is fish recruitment related to spawner abundance? Fish Bull 94:707-724

Myers RA, Barrowman NJ, Hutchings JA, Rosenberg AA (1995) Population dynamics of exploited fish stocks at low population levels. Sciences 269:1106-1109

Pepin P, Orr DC, Anderson JT (1997) Time to hatch and larval size in relation to temperature and egg size in Atlantic cod (Gadus morhua). Can J Fish Aquat Sci 54(Suppl 1):2-10

Ricker WE (1954) Stock and recruitment. J Fish Res Board Can 11:559-623

Ruzzante DE, Taggart CT, Cook D, Goddard S (1996) Genetic differentiation between inshore and offshore Atlantic cod (Gadus morhua) off Newfoundland: microsatellite DNA variation and antifreeze level. Can J Fish Aquat Sci 53: $634-645$

Sæmundsson B (1924) Fiskarnir (Pisces Islandiae). Felgasprentsmidjan, Reykjavik

Schopka SA (1994) Fluctuations in the cod stock off Iceland during the twentieth century in relation to changes in the fisheries and environment. ICES Mar Sci Symp (Act Symp) 198:175-193

Sinclair M (1988) Marine populations. An essay on population regulation and speciation. Washington Sea Grant Program, University of Washington Press, Seattle

Sparholt H (1996) Causal correlation between recruitment and spawning stock size of central Baltic cod? ICES J Mar Sci 53:771-779

Stephenson RL (1999) Stock complexity in fisheries management: a perspective of emerging issues related to population sub-units. Fish Res 43:247-249

Sundby S, Bjørke H, Vold Soldal A, Olsen S (1989) Mortality rates during the early life stages and year-class strength of northeast Arctic cod (Gadus morhua L.). Rapp PV Réun Cons Int Explor Mer 191:351-358

Suthers IM, Sundby S (1993) Dispersal and growth of pelagic juvenile Arcto-Norwegian cod (Gadus morhua), inferred from otolith microstructure and water temperature. ICES J Mar Sci 50:261-270

Sveinbjörnsson S, Jónsson SP (1998) Report on the 0-group fish survey in Icelandic waters, August 1998. ICES CM D:13

Valdimarsson H, Malmberg SA (1999) Near-surface circulation in Icelandic waters derived from satellite tracked drifters. Rit Fiskideild 16:23-39

Vilhjalmsson H, Fridgeirsson E (1976) A review of 0-group surveys in the Icelandic-East Greenland area in the years 1970-1975. ICES Co-op Res Rep 54:1-34

Vilhjalmsson H, Magnusson JV (1984) Report on the 0-group fish survey in Icelandic and East Greenland waters, August 1984. ICES CM H:66

Vilhjalmsson H, Magnusson JV (1985) Report on the 0-group fish survey in Icelandic and East Greenland waters, August 1984. ICES CM H:75

Submitted: October 18, 1999; Accepted: March 21, 2000

Proofs received from author(s): August 4, 2000 